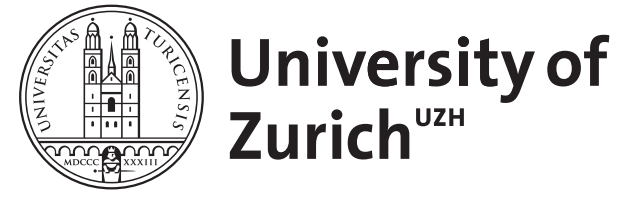

Zurich Open Repository and Archive

University of Zurich

University Library

Strickhofstrasse 39

CH-8057 Zurich

www.zora.uzh.ch

Year: 2013

\title{
Jaw musculature during the dawn of turtle evolution
}

\author{
Werneburg, Ingmar
}

DOI: https://doi.org/10.1007/s13127-012-0103-5

Posted at the Zurich Open Repository and Archive, University of Zurich

ZORA URL: https://doi.org/10.5167/uzh-93108

Journal Article

Published Version

Originally published at:

Werneburg, Ingmar (2013). Jaw musculature during the dawn of turtle evolution. Organisms Diversity Evolution, 13(2):225-254.

DOI: https://doi.org/10.1007/s13127-012-0103-5 


\title{
Jaw musculature during the dawn of turtle evolution
}

\author{
Ingmar Werneburg
}

Received: 29 February 2012 / Accepted: 14 June 2012 /Published online: 1 August 2012

(C) Gesellschaft für Biologische Systematik 2012

\begin{abstract}
Using a new approach to study muscle anatomy in vertebrates, the fully differentiated jaw musculature of 42 turtle species was studied and character mappings were performed. Soft tissue arrangements were correlated to the temporal openings (emarginations) of the skull and the trochlearis system of the jaw apparatus among turtle taxa. When compared to the cranial anatomy of stem Testudines, most characters detected as diagnostic of particular extant groups have to be considered as being evolved first within Testudines. Hence, jaw muscle anatomy of extant turtles is difficult to compare to that of other reptilian taxa. Moreover, the high number of apomorphic character changes speaks for a divergating turtle and saurian morphotype of jaw musculature, which could indicate either a position of turtles outside of Sauria or a highly derived, undetectable origin within that group. In general, a low direct correlation of most soft and hard tissue characters was detected. This finding could imply that both character complexes are more integrated to each other driven by functional morphology; i.e., the composition of muscle fibre types. That condition highlights the difficulty in using gross anatomy of jaw muscle characters to interpret temporal bone arrangements among amniotes in general.
\end{abstract}

Keywords Cryptodira · Pleurodira · Character mapping · Musculus adductor mandibulae - Temporal skull region . Feeding $\cdot$ Testudinata $\cdot$ Trochlearis system $\cdot$ Fossil turtles

I. Werneburg $(\bowtie)$

Fachbereich Geowissenschaften der Eberhard Karls Universität Tübingen,

Hölderlinstraße 12,

72074 Tübingen, Germany

e-mail: i.werneburg@gmail.com

I. Werneburg

Paläontologisches Institut und Museum der Universität Zürich,

Karl Schmid-Strasse 4,

8006 Zürich, Switzerland

\section{Introduction}

The origin and interrelationship of turtles have been debated intensively (e.g., Rieppel 2008; Werneburg and SánchezVillagra 2009; Werneburg 2010; Scheyer et al. 2012) but, besides osteological and molecular data (e.g. Gaffney 1975; Gaffney et al. 1991; Joyce 2007; Lyson et al. 2010; Thomson and Shaffer 2010; Sterli 2010), only a few other character complexes have been used to reconstruct turtle phylogeny. I studied the jaw musculature as being a potential new source of phylogenetic information. A better understanding of soft tissue morphology (herein: musculature and tendons) may help in detecting relationships to skeletal transformations, functional adaptations, and evolutionary transitions of turtle and vertebrate heads in general.

The most prominent and most commonly studied muscular structures of vertebrates are those innervated by $n$. trigeminus $(\mathrm{V})$, resulting in a great diversity of classificatory schemes (exemplified for turtles in Fig. 1). The trigeminal jaw musculature can be subdivided into three parts (Vetter 1878; Lubosch 1933, 1938a, b; Luther 1938; Rieppel 1981). First, the Constrictor primus $\left(\mathrm{C}_{1}\right)$ dorsalis homologue of Chondrichthyes, which is largely reduced in turtles [but see Fig. 2B/right, m. levator bulbi (No. 16) in Dermochelys coriacea, for numbers of muscular units see Fig. 1 and Werneburg (2011)] and spans between the palatal and the postorbital region of the cranium.

Second, the Constrictor primus lateralis homologue is represented by the jaw adductor musculature (Fig. 1), parts of which can be elongated extensively along the crista supraoccipitalis and crista squamosalis in several turtle groups (e.g., Kilias 1957; Gaffney 1975; Rieppel 1990). This extension and related changes in bite stresses were often assumed to be in the cause of the loss of various dermatocranial elements resulting in a caudal or/and a lateral emargination (e.g. Zdansky 1923-1925; Kilias 1957; reviewed 


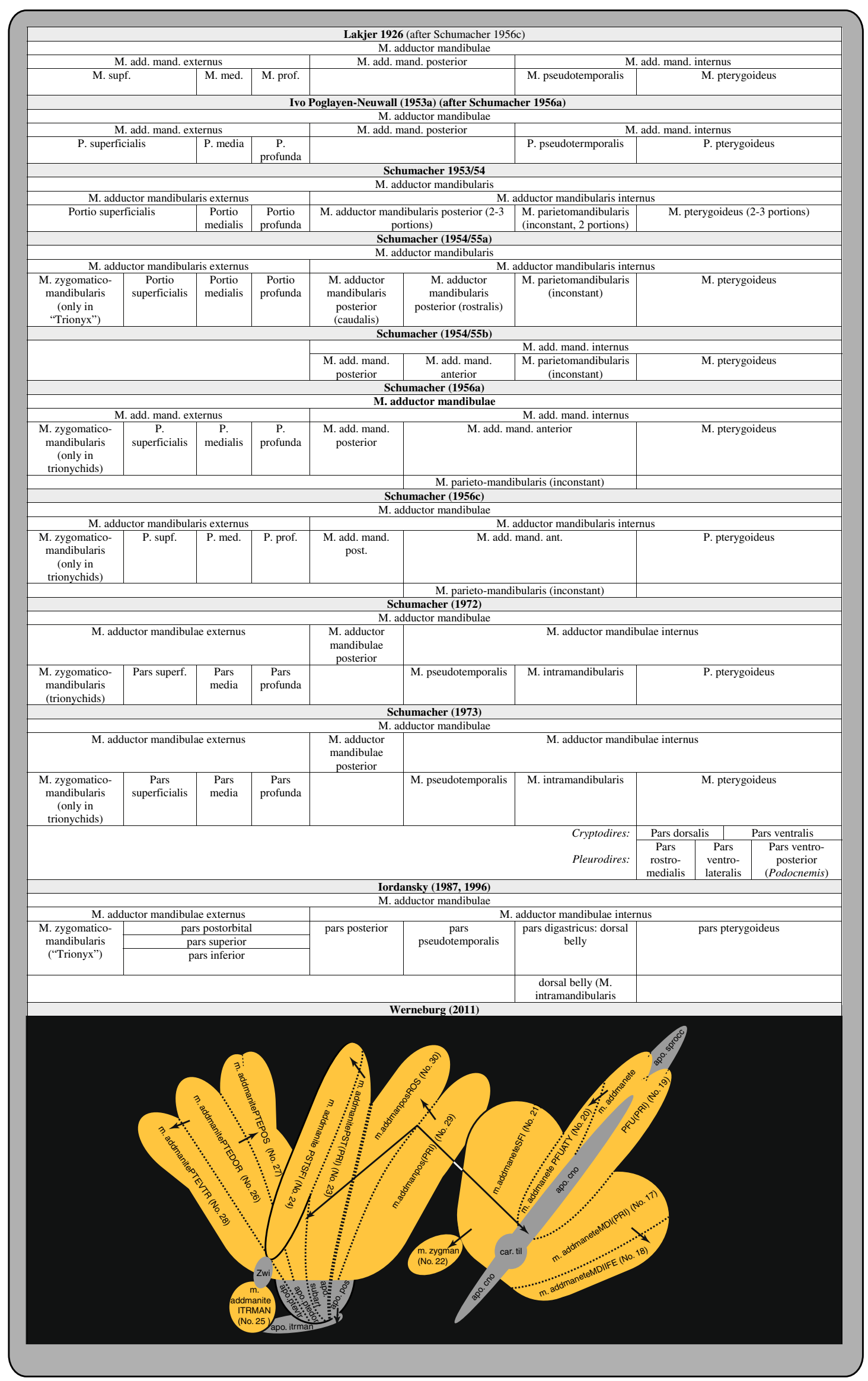


4 Fig. 1 Scheme listing different arrangements of $\mathrm{m}$. adductor mandibulae structures (Constrictor primus lateralis) proposed for turtles in the literature. The abbreviations of words follow the style of Schumacher (1953/ 1954-1985). German words are translated. Note the "historically" shifting categorisation of $\mathrm{m}$. adductor mandibulae externus posterior ("M. add. mand. posterior") in relation to the other muscular structures; also, the parts of $\mathrm{m}$. adductor mandibulae internus are categorised differently. Below The jaw musculature of turtles is presented following the lotus approach (modified from Werneburg 2011, see text for details)

by Werneburg 2012) and were correlated to a potential secondary loss of skull fenestration. The Constrictor primus lateralis consists of mm. adductor mandibulae externus et internus et posterior in turtles. The identity of the divisions of those muscles has often been discussed in such a way as to result in an inconsistent nomenclature in the literature (Fig. 1; Werneburg 2011). Lakjer (1926) developed a jaw muscle nomenclature for all Sauropsida based on the relative position of these muscles to the branches of the $\mathrm{n}$. trigeminus (V) (e.g. see Holliday and Witmer 2007). Recently, Iordansky (1994) thoroughly proposed to categorise jaw muscles thoroughly based on the shape and differentiation of the tendinuous framework that bears these muscles (see Werneburg 2010). On the one hand, the coronar aponeurosis, which attaches around the coronoid of the lower jaw, bears portions of $\mathrm{m}$. adductor mandibulae externus (Fig. 2B) (No. 17-22). On the other hand, the m. adductor mandibulae internus (Fig. 1) and its portions (No. 23-28) insert into the subarticular aponeurosis, which attaches medially to the posterior part of the lower jaw. A separation of the pterygoidal aponeurosis from the subarticular tendon can occur in turtles [Fig. 1 (below)], bearing the pterygoideus parts (No. 26-28) of the $\mathrm{m}$. adductor mandibulae internus complex. Often referred to as a part of the m. mandibulae internus in turtles (Fig. 2), and herein defined as a separated muscle (see Werneburg 2011), the $\mathrm{m}$. adductor mandibulae posterior (No. 29-30) is situated between the mm. adductor mandibulae externus (No. 17-22) et internus (No. 23-28).

The third part of the $n$. trigeminus (V) innervated jaw musculature is the Constrictor primus ventralis homologue, which is represented by only three (No. 31-33) or four [see Werneburg (2011) for discussion on the identity of m. intramandibularis (No. 25)] muscular units that stretch between the dentaries in turtles.

Additional n. trigeminus (V) innervated muscular structures in turtles, not included in the present study, were previously observed in the nasal (No. 11-13) and ocular (No. 14-15) regions. The phylogenetic and developmental origin of those muscles is not entirely clear but may be derived from the Constrictor primus dorsalis and/or from cranial neural crest cell material (Werneburg 2011).

For turtles, there are at least nine different hypotheses for the arrangement of cryptodiran subgroups, and two different hypotheses for chelid (Pleurodira) phylogeny (e.g. summarised by Sánchez-Villagra et al. 2007; Scheyer 2007, 2009; Wilson and Sánchez-Villagra 2011). The pioneering work of
Gaffney and Meylan (1988) was based primarly on bonecharacters resulting in a "basal" position of chelydrids (snapping turtles), incl. Platysternidae (big-headed turtles) within Cryptodira. Their morphological data supported a long-necked and a short-necked clade of chelid pleurodires. Other morphological works differ in the arrangement of Chelydridae, Platysternidae, and Chelonioidea (marine turtles) (Brinkman and Wu 1999; Joyce 2007; Werneburg and Sánchez-Villagra 2009). Since the late 1990s, genetic studies have consistently resulted in a stable chelid phylogeny consisting of distinct South American and Australasian clades (Shaffer et al. 2007; Krenz et al. 2005; Parham et al. 2006; Thomson and Shaffer 2010). All genetic studies also point to a "basal" position of Trionychia (soft-shelled turtles and Carettochelys insculpta) within Cryptodira. The relationship of all remaining cryptodire subgroups remained unclear; however, a molecular consensus is arising that Testudinoidea is the sister taxon to the remaining hard-shelled cryptodires with Platysternon megacephalum as a sister taxon to the Emydidae. Chelonioidea, Chelydridae, and Dermatemys mawii form the successive outgroup taxa of Kinosternidae.

Up to now, no phylogenetic study has considered the evolution of jaw musculature within turtles. Among other reasons discussed below, a diffuse nomenclature that lacked explicit primary homology assessments (de Pinna 1991) hindered phylogenetic inference. In a recent study, I reviewed all available literature references relating to the cranial musculature of turtles (Werneburg 2011). By atomising macroscopic structures into so-called muscular units, a traceable system on how to deal with muscular structures in phylogenetic research was developed. Having a plastic concept of muscular development and evolution in mind (Fig. 1 below; Werneburg 2011), the study presented here aims to test the phylogenetic signal of soft tissue characters in understanding turtle phylogeny and, more importantly, the correlation between the jaw musculature, the tendinous framework, and skull anatomy.

\section{Materials and methods}

Character definitions, coding strategies, and taxonomic sampling

I coded characters for those cranial muscles that are generally the most extensively studied among Tetrapoda, i.e. the n. trigeminus $(\mathrm{V})$ innervated jaw musculature (No. 17-31) and the $\mathrm{n}$. facialis (VII) innervated $\mathrm{m}$. depressor mandibulae (No. 45). Information on other cranial muscles is available for only very few turtle species. Hence, I reduced the number of characters in order to have a broader sample of taxa, of which most characters are known.

The plastic nature of cranial musculature (Fig. 1, bottom; Werneburg 2011) is hard to code as discrete characters and 
coding strategies that are used for bony structures are not applicable here. As such, several alternative character coding approaches could be developed, all of which have advantages and disadvanteges (sensu Pleijel 1995). I decided on three alternative coding strategies, and estimated their influence on character distribution.

In coding-1, I present a largely phenetic/numerical approach coding mostly the absence (0) / presence (1) of muscle attachment to a bone (Appendices 1 and 2). Based on my own observations on Emydura subglobosa and on a comprehensive literature review (Werneburg 2011), I defined 202 characters (Appendix 1) for 42 turtle species (Table 1). The jaw muscles of all taxa were either described in detail and/or the depictions presented by the authors were sufficient to code character states clearly (Appendix 2, Fig. 2). The characters describe mainly the origin and insertion patterns of muscular units. Information on innervation pattern or fibre course would be valuable, but due to the restricted focus of several authors, such information is currently unavailable for most species.

In coding-2 (Appendices 3 and 4), I transferred the absence/ presence-characters of coding-1 into an alternative shape, namely attachment of muscle X to bone A (0), to bone B (1), to bone $\mathrm{C}$ (2), etc. For all species, this coding strategy, with 74 characters, resulted in several multiple character states, which are not informative in phylogenetic analyses (Kornet and Turner 1999; Swofford 2003). As such, I present a third coding approach derived from coding-2, in which each composition of multiple character states of coding-2 was transferred into a new character state, coded as a letter (Appendix 4).

For the initial, coding approach (coding-1; Appendices 1 and 2), I decided on the following: where not explicitly stated, direct muscle fibre attachments were coded. Non-applicable character states were included in the character matrix (Appendix 2) only when a whole structure, such as a bone or a muscular unit, was missing. For turtles (not outgroup taxa), all possible attachments were coded. If one character state is coded for only one species, the character becomes parsimony uninformative in a phylogenetic reconstruction. However, I kept those uninformative characters in the matrix, firstly to retain as much information as possible to document the anatomy of terminal taxa and, secondly, to document that a muscle attaches to a particular site in contrast to none. In addition to a detailed character, e.g. "attaches laterally to element A (0) or not (1)", I could have defined an absent/present character beforehand, e.g. "attaches to that element A (0) or not (1)". This coding strategy would have (1) transferred the detailed characters to become non-independent, and (2) resulted in taxa that were coded as inapplicable for several characters. However, whether a muscle generally attaches to an element or not is often the only information available in the literature. By using the presented strategy, namely coding all possible attachments, I also indirectly present information on the general attachment to an element: if all possible attachment sites are coded as "not
Fig. 2 Examples of the diversity of jaw musculature in the major taxa of Testudines in lateral (most images) or dorsolateral (f, i, k: right images) view. Topology follows Shaffer (2009), which is the preferred topology herein. Left pictures each demonstrate the arrangement of $\mathrm{mm}$. adductor mandibulae externus (No. 17-22) et depressor mandibulae (No. 45); the right picture for each clade demonstrates the arrangement of $\mathrm{m}$. adductor mandibulae internus (No. 23-28) et posterior (No. 29-30). In $\mathbf{g}$ and $\mathbf{j}$, the m. constrictor colli complex (No. 4043, also indicated in c), m. intermandibularis (No. 31), and m. branchiomandibularis visceralis (No. 47) are also visible. $\mathbf{c}$ and $\mathbf{g}$ also show epaxial muscles. Images modified and redrawn from a Lakjer (1926: figures 151-153): Amyda cartilaginea, b Lakjer (1926: figures 51, 149-150): juvenil Dermochelys coriacea, c Rieppel (1990: figure 1A-B, E): Chelydra serpentina, d Poglayen-Neuwall (1953a: figures 1D, 2 G): Kinosternon scorpioides, e Lakjer (1926: figures 139, 228): Chelonoidis denticulata, f Poglayen-Neuwall (1953a: figures 2D, 3B): Cuora amboniensis, g Iordansky (1987: figures 1A, 1 F): Trachemys terrapen, h Schumacher (1954/55a: figure III2, 1954/55b: figure III2): Platysternon megacephalum, i Poglayen-Neuwall (1953a: figures 1B, 5A): Mesoclemmys nasuta, j Iordansky (1996: figures 2a, e): Pelomedusa subrufa, k Podocnemis expansa-Schumacher 1973: figure 9, Schumacher 1972: figure IX2): Podocnemis expansa. In a and c, the zygomatic arch is removed. In $\mathbf{b}, \mathbf{h}$, and $\mathbf{k}$ the postorbital and the temporal dermatocranial armour are removed

present", the muscular unit generally does not attach to the element. If the structure attaches to an element, but the detailed attachment site is unknown, I coded the character as "?". These coding strategies should be taken into consideration when interpreting character distribution on a phylogenetic tree.

For some species, I had information on different stages of development, including hatchlings, juveniles/subadults, and adults. To enable a certain amount of comparability, I coded the most adult condition of a character as documented in the literature.

The dorsad-leading part of the lower jaw is built mainly by the "coronoid area". Possibly due to phylogenetic or ontogenetic variation, it may be represented by a coronoid process of the dentary or a coronoid bone. A clear definition of this "coronoid area" is mostly not documented in the literature; hence, I synonymised 'coronoid' and 'coronoid process of the dentary' in the character list as "coronoid" (Appendix 1).

\section{Non-turtle taxa}

Holliday and Witmer (2007: Tables 2,3) presented a thorough and detailed summary of the jaw muscle attachments for three saurian clades - Lepidosauria, Crocodylia, and Neornithesresulting from a literature review and their own observations. As the aim of my study was to observe the distribution of muscular characters within Testudines, I handled those three taxon summaries as terminal taxon descriptions. This decision leads, on the one hand, to a limitation in that the diversity in those clades, especially in lizards and birds, is not represented accurately, and the taxon summaries of Holliday and Witmer (2007), which are not based on a phylogenetic analysis, may therefore not necessarily represent the ground pattern of the respective groups. As these latter authors had a different aim 


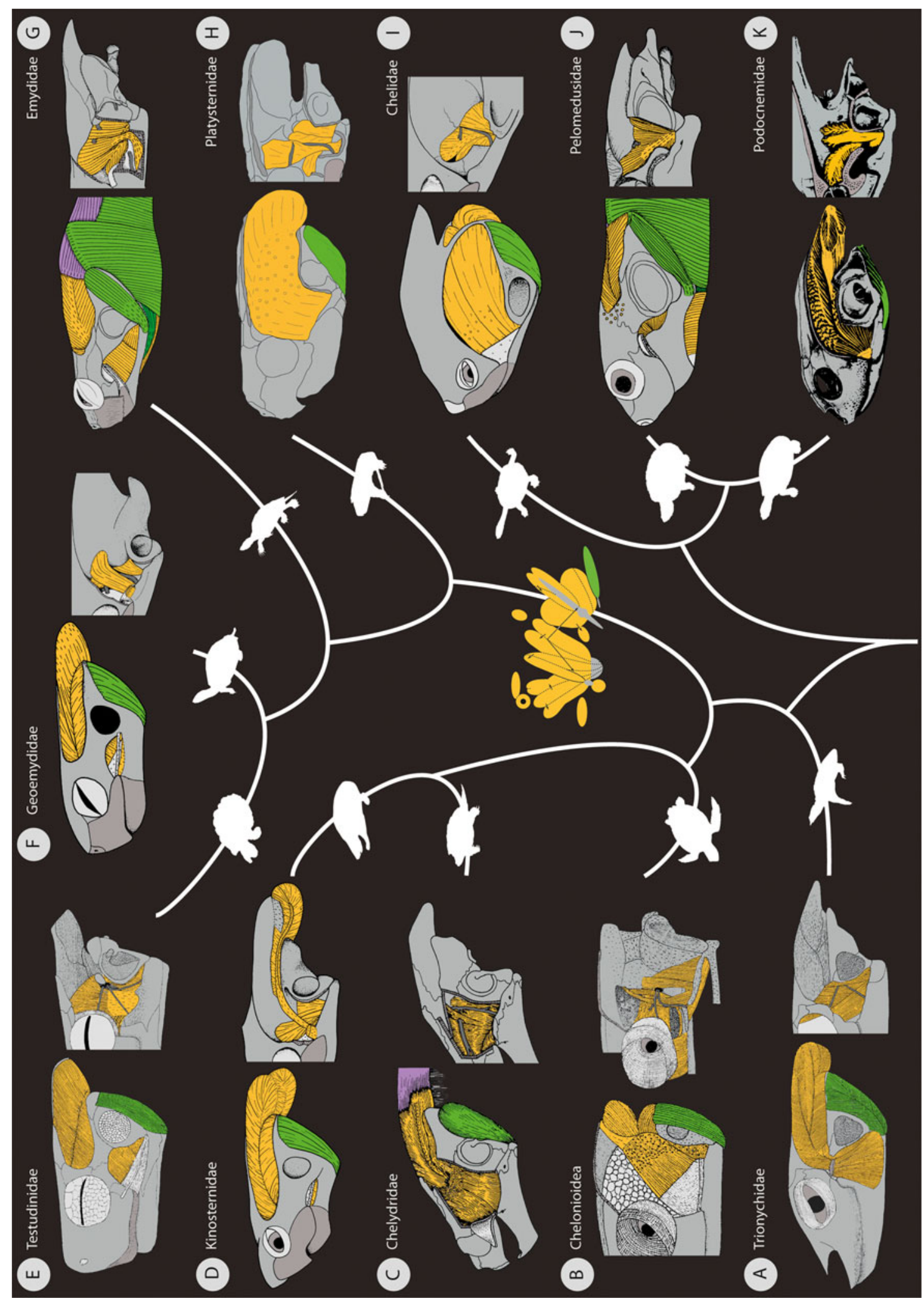


Table 1 Species analysed for phylogenetic analyses and the related references in chronological order. Taxonomic synonyms follow Fritz and Havaš (2007). For phylogenetic arrangements of the taxa in the preferred topology see Fig. 3

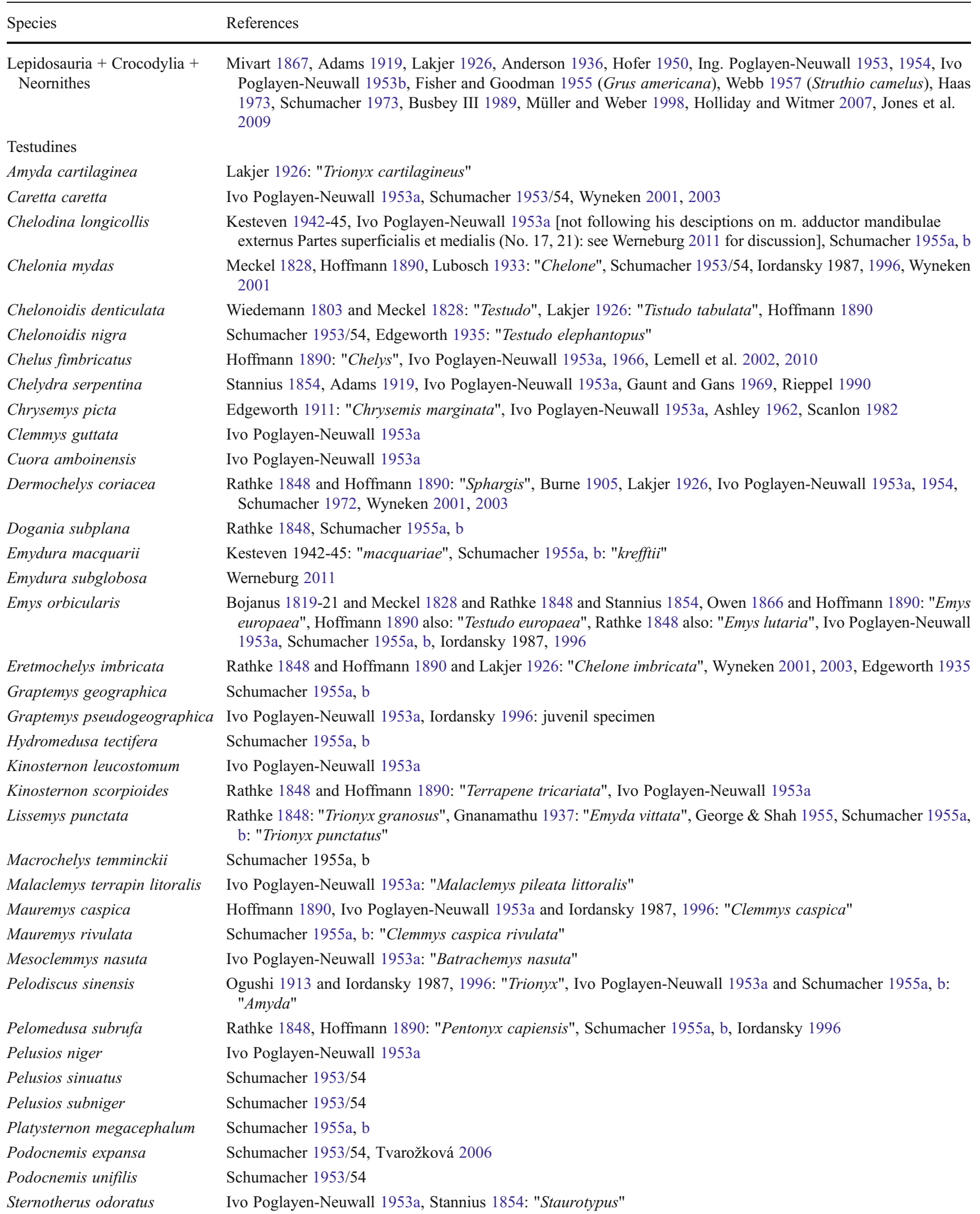


Table 1 (continued)

\begin{tabular}{ll}
\hline Species & References \\
\hline Terrapene carolina & Lakjer 1926: "Cistudo", Ivo Poglayen-Neuwall 1953a: "triunguis" [not following his desciptions on m. adductor \\
& mandibulae externus Partes superficialis et medialis (No. 17, 21)] \\
Testudo graeca & Hoffmann 1890: Testudo craeca et "Testudo mauretanica", Rathke 1848, Burkard 1902, Thomson 1932, Lubosch \\
& 1933, Ivo Poglayen-Neuwall 1953a, Hacker 1954, Hacker and Schumacher 1954, Schumacher 1955a, b \\
Trachemys scripta & Meckel 1828: "Emys serrata", Ivo Poglayen-Neuwall 1953a: "Pseudemys" \\
Trachemys terrapen & Iordansky 1987, 1996: "Pseudemys terrapen" \\
\hline
\end{tabular}

in their study, they did not present the variability of characters among and within species in detail. The use of particular species of birds, lepidosaurs, and crocodiles may have been the better solution. However, I am not an expert in those groups and by using the thorough description by Holiday and Witmer I prevent misinterpretations in these taxa whose anatomy is a subject in itself. It would have been preferable to use outgroup taxa whose characters are based on a phylogenetic analysis, but producing this data was beyond the scope of this paper. All these considerations should be kept in mind when interpreting the output of the phylogenetic analyses presented here. Further studies should address saurian muscle characters in detail, which will require a detailed literature review and phylogenetic analyses.

For Lepidosauria, I extended the dataset of Holliday and Witmer (2007) with the information on Sphenodon punctatus (Rynchocephalia) presented by Jones et al. (2009), who also documented intraspecific variation. Other recent papers on the jaw muscles of lepidosaurs and other tetrapods were published by Daza et al. (2011) and Johnston (2011a, b).

For information not presented in the study of Holliday and Witmer (2007), I considered some other studies as summarised in Table 1. For muscle ratio-data (Appendix 1: characters 2-8), I compared published figures on selected representatives, namely $S$. punctatus, Iguana iguana (Lepidosauria), Alligator mississippiensis (Crocodylia), Grus americana and Struthio camelus (Neornithes).

For muscle-homologisations among sauropsids, I refer mainly to Holliday and Witmer (2007). I did not revise the literature cited by the authors, but their homologisation appears to be well founded. Nevertheless, particularly the homology of the $\mathrm{m}$. adductor mandibulae internus Pars pterygoideus dorsalis $/ \mathrm{m}$. pterygoideus anterior remains contested by developmental studies and observations of the innervation pattern (Iordansky 1964, 2008, 2010; Tvarožková 2006). Moreover, current knowledge of the jaw musculature of tetrapods is very limited. There are several detailed studies on particular taxa (e.g. Poglayen-Neuwall 1953a; Iordansky 1987; Haas 2001, 2003a, b; Diogo and Wood 2011); however, they have not yet resulted in a cranial musculature based phylogenetic reconstruction of all tetrapods. I suggest critically rechecking the very influential categorisation of Lakjer (1926) (e.g. Lubosch 1933; Rieppel 1981, 1987; Holliday and Witmer
2007; Jones et al. 2009), who separated the $\mathrm{n}$. trigeminus (V) innervated jaw musculature of sauropsids into three parts. Comparative developmental studies (Edgeworth 1935; Rieppel 1990; Tvarožková 2006) will need to be expanded.

For Sphenodon punctatus, I homologised the ' $\mathrm{m}$. Pterygoideus Typicus Middle Medial' (m.PtTyMM) of Jones et al. (2009) to the herein presented $\mathrm{m}$. adductor mandibulae internus Pars pterygoideus posterior (No. 27) due to similarities in the attachment sites and the relative positions of both structures to the surrounding tissues.

\section{Character mappings}

Using PAUP* (Swofford 2003), I plotted the coded soft tissue characters of my study onto a composed topology (Fig. 3) drawn with Mesquite 2.72 (Maddison and Maddison 2007). The topology derived from Shaffer (2009) for major turtle taxon relationships and Iverson et al. (2007) for the arrangements of "genera" and species (Fig. 3). I calculated Acctran and Deltran optimisations. As outgroup to Testudines, I defined [Lepidosauria $+($ Crocodylia + Neornithes $)]$.

\section{Results and discussion}

Musculature and phylogeny

Relatively few studies (e.g. Winterbottom 1974; Estes et al. 1988; Hoyos 1990; Abdala and Moro 1996; Haas 2003a, b; Diogo 2004, 2007; Diogo et al. 2008a, b; Hertwig 2008; Werneburg 2009, Johnston 2011a) have extensively integrated soft tissue characters to reconstruct phylogenies. Among the reasons for this, these causes seem relevant (e.g. Hertwig 2008; Diogo and Abdala 2010; Werneburg 2011): (1) Inadequate, incomparable nomenclature resulting in terminological confusions in the literature; (2) uncertainties about homologies; (3) the challenge of gathering a broad set of information based on detailed manual dissections and histological serial sections; (4) an assumed, never tested, high degree of variability, (5) incomparability (non-homology) of muscular structures among clades.

It is generally believed that musculature is strongly exposed to adaptations such as locomotion, feeding behaviour, 


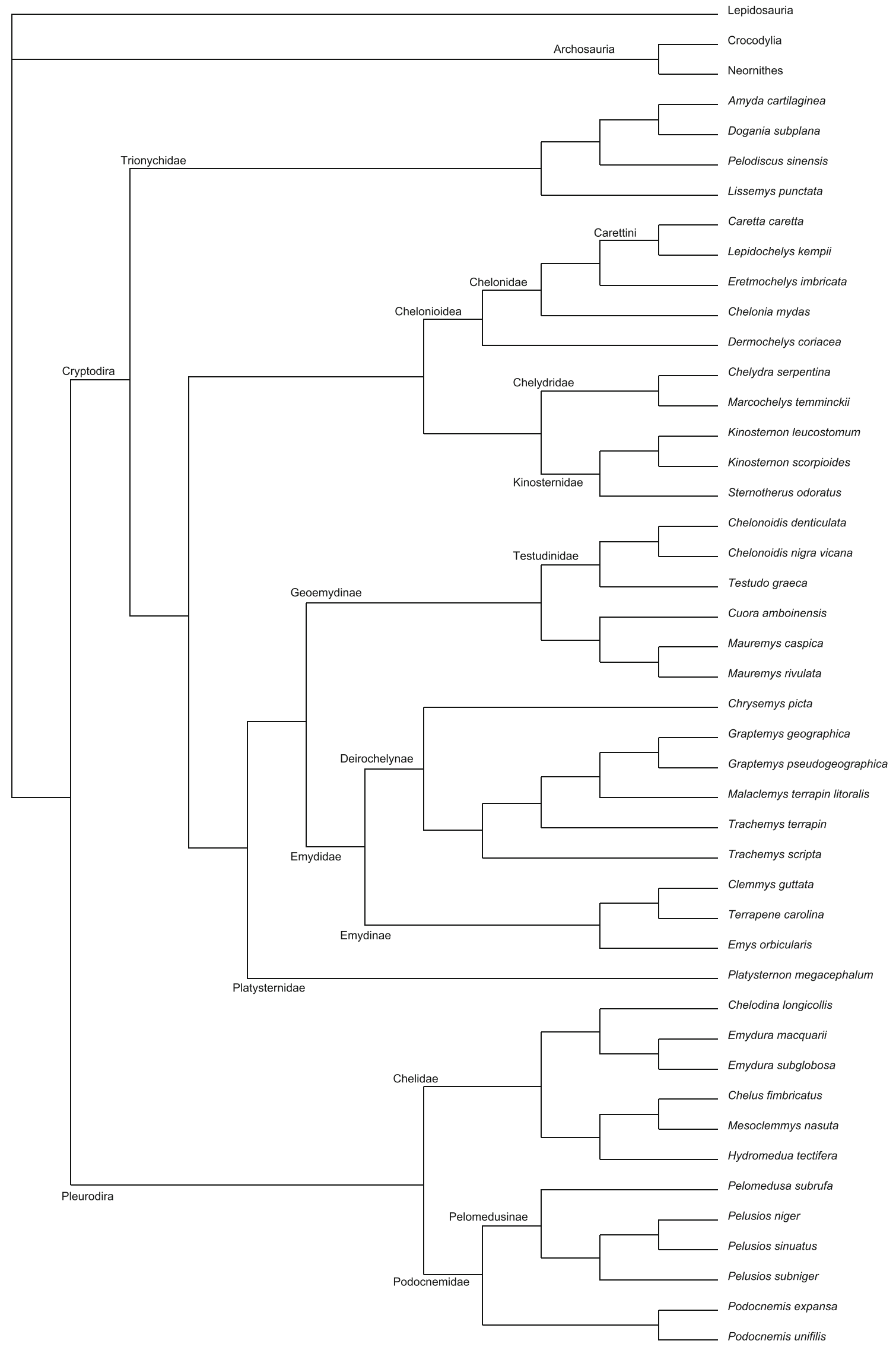


Fig. 3 Composed, preferred topology of this study. Taxon arrangement follows the propositions of Shaffer (2009) and Iverson et al. (2007). A basal position of Trionychia within Cryptodira, as well as the sister group relationships of (Platysternidae + Testudinoidea), (Chelonioidea $+($ Chelydridae + Kinosternidae) and (South American chelids + Australian chelids) are suggested

and ecophysiological demands (molluscivory vs. piscivory vs herbivory), resulting in several homoplastic character states in evolution. To a certain extent, this may be true, but hard tissue material underlies adaptive processes in development and evolution too, whilst muscles may keep a conservative condition (Costelli 1973: cited after Abdala and Moro 2003; Diogo and Abdala 2010). Moreover, the general shape of a muscular structure may stay constant within a major taxon, while the attachments - as mostly coded in the presented study - may be highly variable (Poglayen-Neuwall 1954), and vice versa.

One has to consider the taxonomic level when referring to the phylogenetic signal of any character including molecular, hard, and soft tissue material (e.g. Abdala and Moro 2003; Hertwig 2008). Only total evidence analyses, combining different kinds of data sets and using character congruence in the search, will be able to detect the best-fitting hypothesis for all of the available characters (e.g. Eernisse and Kluge 1993; Frost et al. 2006; Hertwig 2008; Asher et al. 2010). The presented contribution of jaw muscle characters of turtles did not aim to present a new phylogenetic hypothesis for the interrelationship of this group, and PAUP* reconstructions failed to recover any of the commonly accepted clades of turtle subgroups. As such, a character mapping on a given topology was performed (Fig. 3, Table 2).

The characters defined in the present study are gathered mainly from a literature review; hence, the descriptions of the respective authors had to be interpreted, and character states could be defined based only on the accuracy of those studies. For the initial coding, coding-1, I coded mostly simple binary characters.

In the future, the set of characters presented here could be combined with osteological and molecular characters to test hypotheses of turtle interrelationships and to estimate the phylogenetic signal and the relationship of different character sets on different levels of phylogeny. One may argue against such a combining method, as bone and muscle complexes could be non-independent. Muscular structures attach to defined areas of the bones and could influence their anatomy. On the other hand, skeletal shapes influence the extent of muscular structures. However, this problem usually exists when defining any morphological complex in a cladistic sense. Bones contact other bones, which, for this reason, cannot attach to another bone, etc.

Future studies could thoroughly define bone characters in the adductor chamber region with respect to the soft tissue characters defined herein. I refrained from simply combining my muscle data set with published data sets on cranial bone characters (e.g. Gaffney et al. 1991; Joyce 2007). Regarding the details defined for soft tissue anatomy herein, comparably detailed bone characters, such as the ratios of bony contacts in the lower jaw or small tuberosities and "rippled" areas, which may be correlated to attachment sites (e.g. the articular), need to be defined. Moreover, a future study could focus on internal bone structures such as Sharpey's fibres. With such a detailed approach, internal muscular characters could also indirectly be inferred (see also discussion below).

Each of the studies dealing with a set of muscle characters observed by the authors themselves (Abdala and Moro 1996, 2003; Hoyos 1990, 1998, 1999; Haas 2001, 2003a, b; Diogo 2008; Hertwig 2008) is internally consistent (scientifically and terminologically) and leads to traceable results. However, this has so far hindered a combined analysis for several vertebrate groups. The muscle nomenclature and the table of homology for turtles by Werneburg (2011) presented the first critical summary of a broad set of literature references and will enable broader analyses of comparative muscle anatomy in the future. I hope that the approach presented herein, using a plastic model of muscular structures (Fig. 1: below), will be useful when interpreting intra- and interspecific and evolutionary patterns of morphological structures of vertebrates in general.

Using atomised characters for phylogenetic reconstructions

Besides the character mapping, phylogenetic reconstructions were performed using PAUP*, resulting in different topologies (not shown). Those topologies deviate strongly from more plausible topologies and commonly accepted clades. Different considerations are required to adequately interprete the unsuccessful results of these phylogenetic reconstructions:

(1) The more plausible results could be wrong. This, however, is less likely as many clades are confirmed both by osteological and molecular data;

(2) The codings of characters presented herein might not be adequate for phylogenetic reconstructions. As pointed out by Pleijel (1995), Wiens (2000), and many others, the definition of character states indeed has an important influence on the output of a phylogenetic analysis. As reviewed by those authors, and many others, none of the coding strategies (e.g. atomised/multiple characters, absent/present characters, ordered characters) can be favored either on first principles or based on existing empirical evidence, so they recommend that the author of each analysis decides which strategy is best to use. The focus of the present paper is descriptive rather than phylogenetic. The illustration of the distribution of characters among turtle phylogeny presents hypotheses of primary homology and treatments, which are explicit and represent the first comprehensive study using muscle characters in turtle phylogenetic research. Future workers could revise 
Table 2 Characters supporting Testudines, Pleurodira, and Cryptodira in the composed topology (Fig. 3) as inferred by the three alternative character codings. \# Coding strategy; 1, 2, 3 coding strategy -1,- 2, -3;
$A$ Acctran optimisation; $C h$ character; $D$ Deltran, $C$ consensus of Acctran and Deltran, $O$ optimisation method

\section{\# $\mathrm{O} \quad \mathrm{Ch}$ Character changes}

Testudines

1-3 C 1 M. levator bulbi (No. 16). Structure is present (1) $==>$ absent (0)

3 Ratio of $\mathrm{m}$. adductor mandibulae externus portions (No. 17-21). The origin site of Pars profundus (No. 19) extends more caudad than the origin site of Pars medialis (No. 17): other way around (0) $\rightarrow$ yes (1)

1 C 10 M. adductor mandibulae externus Pars medialis (No. 17). Origin of extends to the rostral face of the quadrate: no (0) $\rightarrow>$ yes (1)

33 M. adductor mandibulae externus Pars profundus (No. 19). Origin extends to the supraoccipitale: no (0) $=\Rightarrow$ yes (1)

83 Coronar aponeurosis inserts to the dentary: no (0) $\rightarrow$ yes (1)

90 M. adductor mandibulae internus Pars pseudotemporalis principalis (No. 23). Origin extends to the processus descendens parietalis: no $(0)=>$ yes $(1)$

113 M. adductor mandibulae internus Pars pseudotemporalis superficialis (No. 24). Insertion extends around the insertion of the coronar aponeurosis (coronar aponeurosis, cartilago transiliens, surangular, and / or coronoid process): yes $(1)==>$ no $(0)$

144 M. adductor mandibulae internus Pars pterygoideus ventralis (No. 28). Insertion extends to the angular: yes (1) $==>$ no $(0)$

148 M. adductor mandibulae internus Pars pterygoideus ventralis (No. 28). Insertion extends to the pterygoid tendon: no (0) $==>$ yes (1)

154 M. adductor mandibulae posterior (Pars principalis) (No. 29). Origin extends to the prootic: no (0) $==>$ broadly to the prootic (1)

159 M. adductor mandibulae posterior (Pars principalis) (No. 29). Insertion extends to the angular: yes (1) $==>$ no $(0)$

A 26 M. adductor mandibulae externus Pars medialis (No. 17). Insertion extends to the posterior face of the coronar aponeurosis: no (0) $\rightarrow>$ yes (1)

51 M. adductor mandibulae externus Pars superficialis (No. 21). Origin extends to the medial face of the quadratum: no (0) $\rightarrow>$ yes (1)

73 M. adductor mandibulae externus Pars superficialis (No. 21). Insertion extends to the lateral face of the coronar aponeurosis: no (0) $->$ yes (1)

79 Cartilago transiliens within coronar aponeurosis is absent $(0) \rightarrow$ is present and has an articulation with: the pterygoid (1)

111 M. adductor mandibulae internus Pars pseudotemporalis superficialis (No. 24). Insertion extends to the Zwischensehne [with this, also a m. intramandibularis (No. 25) is present]: no (0) $\rightarrow$ yes (1)

152 M. adductor mandibulae posterior (Pars principalis) (No. 29). Origin extends to the quadrate: broadly at anterior surface (0) $->$ restricted to the medial aspect of the anterior surface (1)

157 M. adductor mandibulae posterior (Pars principalis) (No. 29). Insertion extends to the prearticular: no (0) -> yes (1)

182 M. intermandibularis (No. 31) covers anterior region of constrictor colli complex (No. 40-43) superficially: no, homogen transition (2) $->$ muscles do not contact (only connected in area of median raphe (3)

200 M. depressor mandibulae (No. 45). Insertion extends via a tendon to the retroarticular process: no (0) $\rightarrow$ yes (1)

2-3 C $12 \quad$ M. adductor mandibulae externus Pars medialis (No. 17). Insertion extends to the surangular (1) $\rightarrow>$ coronar aponeurosis (3)

19 M. adductor mandibulae externus Pars profundus (No. 19). Insertion extends to the coronoid (0) $\rightarrow>$ coronar aponeurosis (1)

24 M. adductor mandibulae externus Pars superficialis (No. 21). Origin extends to the lateral (0) $\rightarrow$ medial (1) face of the squamosal

41 M. adductor mandibulae internus Pars pseudotemporalis superficialis (No. 24). Insertion extends around the insertion of the coronar aponeurosis (coronar aponeurosis, cartilago transiliens, surangular, and / or coronoid process) $(2)=\Rightarrow$ to the Zwischensehne [with this, also a m. intramandibularis (No. 25) is present] (0)

2 C 14 M. adductor mandibulae externus Pars medialis (No. 17). Insertion extends to the dorsal face (0) $\rightarrow>$ lateral face (1) of the surangular

17 M. adductor mandibulae externus Pars profundus (No. 19). Origin extends to the parietal (0) $==>$ supraoccipital (1)

25 M. adductor mandibulae externus Pars superficialis (No. 21). Insertion extends to the surangular (2) $==>$ coronar aponeurosis (3)

34 M. adductor mandibulae internus Pars pseudotemporalis principalis (No. 23). Origin extends to the parietal (not processus descendens part) (0) $\rightarrow$ processus descendens parietalis (1)

35 M. adductor mandibulae internus Pars pseudotemporalis principalis (No. 23). Insertion extends to the coronoid (7) $=\Rightarrow$ subarticular aponeurosis (0)

51 M. adductor mandibulae internus Pars pterygoideus ventralis (No. 28). Insertion extends to the angular (2) $=>$ pterygoid tendon (6)

A 67 M. intermandibularis (No. 31) covers anterior region of constrictor colli complex (No. 40-43) superficially: no, homogen transition (2) $\rightarrow$ muscles do not contact (only connected in area of median raphe (3)

3 C 17 M. adductor mandibulae externus Pars profundus (No. 19). Origin extends to the parietal (0) $\rightarrow>$ parietal and supraoccipital (A)

23 M. adductor mandibulae externus Pars superficialis (No. 21). Origin extends to the dorsal and lateral (B) $\rightarrow$ medial and anterior (D) face of the quadrate

25 M. adductor mandibulae externus Pars superficialis (No. 21). Insertion extends to the dentary, coronoid, and surangular (A) ==> coronar aponeurosis (3).

31 Coronar aponeurosis inserts to the dorsal ( 0 ) $\rightarrow$ to the dorsal, medial, and lateral (B) face of the coronoid (process)

A 22 M. adductor mandibulae externus Pars superficialis (No. 21). Origin extends to the quadratum and quadratojugal (A) $\rightarrow>$ squamosal (2) 
Table 2 (continued)

\# $\quad \mathrm{O}$ Ch Character changes

27 M. adductor mandibulae externus Pars superficialis (No. 21). Insertion extends to the dorsal and lateral (A) $\rightarrow>$ lateral (1)

67 M. intermandibularis (No. 31) covers anterior region of constrictor colli complex (No. 40-43) superficially: yes (1) $\rightarrow>$ muscles do not contact (only connected in area of median raphe (3)

Cryptodira

1 C 53 M. adductor mandibulae externus Pars superficialis (No. 21). Origin extends to the anterior face of the quadratum: no (0) $==>$ yes (1)

54 M. adductor mandibulae externus Pars superficialis (No. 21). Origin extends to the quadratojugal: no $(0)=\Rightarrow$ yes $(1)$

A 61 M. adductor mandibulae externus Pars superficialis (No. 21). Origin extends to the postorbital: no (0) $\rightarrow$ yes (1)

79 Cartilago transiliens within coronar aponeurosis is present and has an articulation with: the pterygoid (1) $\rightarrow$ with the quadratum / prootic (2)

115 M. adductor mandibulae internus Pars intramandibularis (No. 25). Insertion extends to the bones of fossa (canalis) primordialis: no (0) $\rightarrow$ yes (1)

D 79 Cartilago transiliens within coronar aponeurosis is absent (0) $\rightarrow$ with the quadratum / prootic (2)

2-3 A 29 Cartilago transiliens within coronar aponeurosis has an articulation with: the pterygoid (0) $\rightarrow>$ with the quadratum / prootic (1)

37 M. adductor mandibulae internus Pars pseudotemporalis principalis (No. 23). Insertion extends to the dorsal (0) $\rightarrow>$ lateral (2) face of the cartilago Meckeli

39 M. adductor mandibulae internus Pars pseudotemporalis principalis (No. 23). Insertion extends to the dorsal (0) -> ventral (1) face of the coronoid

57 M. adductor mandibulae posterior (Pars principalis) (No. 29). The posterior aponeurosis (also "Sehnenspiegel") inserts to prearticular (1) $\rightarrow$ articular (2)

61 Subarticular aponeurosis. Insertion extends to the dorsal (0) $\rightarrow>$ lateral (1) face of the cartilago Meckeli

2 C 45 M. adductor mandibulae internus Pars pterygoideus dorsalis (No. 26). Muscle fibres insert (next to insertion to the subarticular aponeurosis) to the articular $(0)=\Rightarrow$ prearticular (1)

3 C 43 M. adductor mandibulae internus Pars intramandibularis (No. 25). Insertion extends with a direct attachment to the bones of fossa (canalis) primordialis $(0) \rightarrow$ inserts also by a tendon to that fossa (A)

Pleurodira

1 C 42 M. adductor mandibulae externus Pars profundus (No. 19). Insertion extends to the dorsal face of the coronar aponeurosis: no (0) $\rightarrow>$ yes (1)

181 M. intermandibularis (No. 31). Fibre course of the posterior part of the muscle around $45^{\circ}$ in posteromediad direction: no $(0)==>$ yes (1)

A 23 M. adductor mandibulae externus Pars medialis (No. 17). Insertion extends to the lateral face of the surangular: no (0) $\rightarrow>$ yes (1)

25 M. adductor mandibulae externus Pars medialis (No. 17). Insertion extends to the lateral face of the coronar aponeurosis: no (0) $\rightarrow>$ yes (1)

85 Coronar aponeurosis inserts to the prearticular: no (0) $\rightarrow$ yes (1)

136 M. adductor mandibulae internus Pars pterygoideus posterior (No. 27). Origin extends to the lateral face and/or to the dorsal face of the pterygoid: no (0) $\rightarrow$ yes (1)

D 73 M. adductor mandibulae externus Pars superficialis (No. 21). Insertion extends to the lateral face of the coronar aponeurosis: no (0) $\rightarrow>$ yes (1)

79 Cartilago transiliens within coronar aponeurosis is absent $(0) \rightarrow$ is present and has an articulation with: the pterygoid (1)

182 M. intermandibularis (No. 31) covers anterior region of constrictor colli complex (No. 40-43) superficially: no, homogen transition (2) $\rightarrow$ yes (1)

2-3 C 66 M. intermandibularis (No. 31). Fibre course of the posterior part of the muscle around $45^{\circ}$ in posteromediad direction: no $(0)==>$ yes (1)

A 48 M. adductor mandibulae internus Pars pterygoideus posterior (No. 27). Origin extends to the ventral face of or/and to the posterior face $(0) \rightarrow$ lateral face and/or to the dorsal face of the pterygoid (1)

2 C 27 M. adductor mandibulae externus Pars superficialis (No. 21). Insertion extends to the dorsal (0) $==>$ lateral (1) face of the surangular

60 Subarticular aponeurosis. Insertion extends to the prearticular (2) $\rightarrow$ articular (3)

A 30 Coronar aponeurosis inserts to the coronoid (process) (0) $\rightarrow$ dentary (1)

43 M. adductor mandibulae internus Pars intramandibularis (No. 25). Insertion extends with a direct attachment to the bones of fossa (canalis) primordialis $(0) \rightarrow$ inserts also by a tendon to that fossa (1)

D 67 M. intermandibularis (No. 31) covers anterior region of constrictor colli complex (No. 40-43) superficially: no, homogen transition (2) $\rightarrow$ yes (1)

3 C 28 M. adductor mandibulae externus Pars superficialis (No. 21). Insertion extends to the dorsal (3) $\rightarrow>$ lateral and ventral (D) face of the coronar aponeurosis. 
Table 2 (continued)

\# $\mathrm{O}$ Ch Character changes

A 20 M. adductor mandibulae externus Pars profundus (No. 19). Insertion extends to the medial (0) $\rightarrow>$ posterior face (4) of the coronar aponeurosis

22 M. adductor mandibulae externus Pars superficialis (No. 21). Origin extends to the squamosal (2) $\rightarrow>$ quadratum and squamosal (Q)

D 22 M. adductor mandibulae externus Pars superficialis (No. 21). Origin extends to the quadratum and quadratojugal (A) $\rightarrow>$ quadratum and squamosal (Q)

27 M. adductor mandibulae externus Pars superficialis (No. 21). Insertion extends to the dorsal and lateral (A) $->$ lateral (1) face of the surangular

the matrices. My work may serve as a case study with which to understand and estimate how phylogenetically conserved or homoplastic this kind of character complex is at different levels of taxonomic hierarchy.

I present three alternative coding strategies, which are derived from each other. More sophisticated and pure cladistic character codings may result in more plausible results. Some of the multiple state characters coded herein could certainly be ordered. I refrained from that strategy to reduce ad hoc hypotheses of polarity. In addition, I rely mostly on a literature review. If I had dissected the specimens myself, a more integrative, less atomised/numerical character coding could have been produced, derived from a deeper impression of the actual material.

(3) There might be much homoplasy in the characters defined for phylogenetic reconstructions. Among other functions, all characters are related to feeding and breathing and may be assumed to be influenced strongly by functional adaptations. But what characters are not in biology? Some taxa were 'correctly' reconstructed, which indicates that some characters defined herein are powerful enough to resolve at least different levels of the reptile phylogeny (e.g. Archosauria and Testudines as monophyla; groupings of some turtle "genera"; see Werneburg 2010).

(4) The primary homology statements of the characters could be incorrect, i.e. they do not survive the test of homology in a phylogenetic reconstruction and are hence not secondary homologies (De Pinna 1991). Most characters coded herein refer simply to the attachment of a muscular structure to a bone. This kind of character atomisation might be misleading for phylogenetic reconstructions as the actual attachment of a muscular structure to a particular bone might be less important than a general attachment of that structure to a broader spatial appearance such as the otic region or the postorbital bony bridge in general. But this is a highly subjective approach, which, when coded by different researchers, will result in different phylogenetic reconstructions again.

As mentioned above, the cranial musculature behaves as a plastic structure in evolution and development (Fig. 1, Werneburg 2011), which is hard to code in a cladistic sense.
Using Remane's (1950) approach of homologisation, I discussed the identities of muscular units extensively (Werneburg 2011) based on criteria such as general attachments, fibre courses, ontogeny, and innervation patterns. Given the certain validy of that homologisation (e.g. detailed innervations pattern are known for only a few species), one needs to consider the plasticity of muscle attachments. The material source of a muscle attachment can vary along the whole muscular unit and, depending on the timing and spatial interrelationship of the primordial muscle/bone contact, the actual fibres forming the attachments may not be homologous among species although derived from a homologous muscular unit. The example of jaw muscle attachments presented herein is a case study for the different levels of homology that need to be considered for phylogenetic reconstructions.

\section{Considerations on character mapping}

The character lists and matrices of the three different coding approaches can be found in the Appendix. For the clades Testudines, Cryptodira, and Pleurodira, Acctran and Deltran, optimisations and the consensi of both for all coding strategies can be found in Table 2 .

Pattern cladists dealing with muscle characters "just" run their analyses and listed the resulting derived characters for each node in the resulting phylogenies (e.g. Abdala and Moro 1996). Those trees do not resample any other topologies, which show overlappings between osteological- or molecular-based clades. The characters listed in those papers are rarely cited or discussed in an evolutionary context.

It is a common strategy to plot data, of which the phylogenetic signal is hard to estimate (e.g. Winkler 2006; Scheyer 2009), onto a topology and to discuss those characters as given apomorphies due to the lack of more precise phylogenetic support. However, Assis and Rieppel (2011) critisised "the mapping of morphological characters onto nodes of a molecular tree [as this strategy] results in an empirically empty procedure for synapomorphy discovery". This is because morphological characters are not incorporated into the molecular data matrix in those cases. As such, I should refrain from using the term "apomorphy" in the context of my analysis and rather use a term like "diagnostic character". Nevertheless, 
including 202 or only 74 morphological characters into a matrix of several tens of thousand molecular characters would not change the arrangement of the resulting topology drastically, as such and in actual fact, one finds apomorphies by character mapping.

In plotting anatomical characters onto a more reasonable topology (in which more overlappings of clades derived from different datasets exist), a sound discussion is possible in a traditional, morphological matter. By just following a cladistic approach, no sensible biological discussion is possible with the kind of data presented herein. I am "just" interested in character distribution on given topologies and its possible meaning for the evolution of the adductor chamber of turtles.

The character mappings of the three alternative codings enable different views on character distribution (Table 2). Each mapping reveals different perspectives on how and in which contexts the characters evolved. Certainly, the binary characters of coding 1 present only the gain or loss of an attachment in a phylogenetic framework. The multiple character states of coding 2 result in several equivocal character distributions. In coding-2 and -3, the descriptive information for the pure anatomical distribution of characters is lost.

\section{The position of turtles within Sauropsida}

I refrain from discussing the output of the phylogenetic analysis for non-turtle taxa in detail as they form the outgroup to Testudines entirely. As mentioned above, I used the data of Holliday and Witmer (2007) to score these groups, which represents a summary of a literature review rather than the result of a cladistic analysis. Although this may have a crucial influence on the character distribution, the strikingly different muscle anatomy of the major saurian taxa (Lakjer 1926; Poglayen-Neuwall 1953, 1954; Poglayen-Neuwall 1953b; Fisher and Goodman 1955; Webb 1957; Iordansky 1964, 2000; Haas 1973; Schumacher 1973; Jones et al. 2009) is well reflected in the output of my character mapping.

The high number of characters supporting Testudines in the character mapping (Table 2) indicates major rearrangements of the n. trigeminus (V) innervated jaw musculature within Sauropsida - resulting in a Lepidosauria/Archosauria and a Testudines morphotype, both of which could possibly reflect a sister group relationship of those taxa. Based on my exclusively neontological data, I cannot test whether Testudines evolved within one of the fossil "Anapsida"-clades, on the stemline of Sauria, or even on the stemline of Diapsida (sensu Werneburg and Sánchez-Villagra 2009). A position of turtles within Diapsida on the other hand must also have come along with crucial rearrangements of the jaw musculature, the origin of which cannot be detected with the characters defined herein.

The arrangement of jaw muscle characters as observed in the presented study does not help addressing the question of the origin of temporal bone arrangements in turtles, as the ground pattern of jaw muscle attachments to the temporal region of Testudines did not reveal a strongly divergating shape when compared to other sauropsids. Assuming the Lepidosauria/Archosauria jaw muscle morphotype to be correlated to the diapsid skull condition, turtles either evolved within "Anapsida" or completely rearranged a diapsid dermatocranial armour in concert with a changed jaw muscle arrangement (and vice versa).

Following the preferred topology for turtle interrelationship (Fig. 3, for characters see Table 2), character 83 (coding-1) and character 31 (coding-3) for Testudines may be of particular relevance when interpreting the origin of turtles: the coronar aponeurosis gains an insertion to the dentary and the attachment to the coronoid is expanded. These character changes could have evolved based on a complete rearrangement of the whole $\mathrm{m}$. adductor mandibulae externus complex in turtles when compared to that of the saurian taxa, implying a changed angle of bite forces and possibly a complete rearrangement of muscle precursors in early development of the reptiles. This would support my former hypothesis of a nonhomology of the portions of $\mathrm{m}$. adductor mandibulae externus among Sauropsida (Werneburg 2011). In concert to this, many characters of coding-2 and -3 , such as a changed origin of $\mathrm{m}$. adductor mandibulae externus Pars profundus (No. 19) (character 17) or the changed origin of Pars superficialis (No. 21) on the quadrate (character 24), can also be listed.

The muscular characters as defined herein are not intended to reconstruct the origin and interrelationship of the major turtle taxa using PAUP* (Swofford 2003). At a lower taxonomic level, e.g. "genera", those characters may be of phylogenetic relevance. Gross muscle shape, not extensively coded herein could, on the other hand, be of particular relevance for turtle interrelationship (see Kilias 1957). The discussion of the present study on the phylogenetic signal of the jaw musculature (see above) should not be applied as a general feature to other vertebrate taxa and muscles, as, when compared to other vertebrate groups, turtles show a high degree of cranial diversity, which evolved relatively recently (e.g. Zdansky 1923-1925; Gaffney 1979; Joyce 2007; Werneburg 2012). Among other vertebrate taxa, muscle anatomy contains much phylogenetic signal (e.g. review by Diogo and Abdala 2010; Diogo and Wood 2011).

Lyson et al. (2010) used only the "basal" most fossil turtle species known to reconstruct their amniote phylogeny, resulting in a position of turtles deep within Parareptilia and hence outside of the Sauria-clade. If the latter authors had integrated extant turtle taxa, a high degree of phylogenetic noise would be imaginable, resulting in a differently reconstructed position of turtles within amniotes. This is again because emarginations are a secondary phenomenon among extant turtles involving a high degree of derived jaw muscle characters (Table 2). Future studies using jaw muscle 
characters to reconstruct tetrapod phylogeny should be careful when either using turtles with emarginations or using marine turtles with their mostly complete temporal armour, including related secondary jaw muscle arrangements, which was acquired secondarily (Jones et al. 2012).

The evidence from fossils to interpret jaw muscle evolution in turtles

In general, Testudines are well defined by several derived characters that characterise them as a monophyletic clade (Mickoleit 2004). To what degree most of those characters can be discussed as autapomorphic for all Testudinata [Testudines (Pancryptodira + Panpleurodira) + stem Testudines; terminology sensu Joyce et al. 2004] is uncertain, as fossil preservation is often limited and as soft tissue characters obviously cannot be studied in extinct taxa. This is also true for extinct and stem taxa of groups of lower taxonomic level (Gaffney 1979). However, for the presented study, the recent discovery of the most "basal" known stem turtle Odontochelys semitestacea (Li et al., 2008: 497) is important: "The skull of Odontochelys shows an elongate preorbital region forming a pointed snout [...]. Small and peglike, pointed teeth are present on premaxilla, maxilla, dentary, pterygoid and vomer [...]. The jugal shows a rounded posteroventral margin, indicating a weak ventral excavation of the cheek. The skull table is not excavated posteriorly. The temporal region is not fenestrated. Distinct basipterygoid processes form an open basicranial articulation with the pterygoids. The pterygoid shows a distinct transverse process that may have separated a subtemporal fenestra from a suborbital fossa [...]. The quadrate is weakly concave posteriorly; a cavum tympani is absent." To what degree $O$. semitestacea shows a derived or juvenile condition ( $\mathrm{Li}$ et al. 2008; Scheyer et al. 2012) cannot be discussed adequately herein. The presumably second most "basal" turtle is Proganochelys quenstedti (Gaffney 1990), which, together with (and as a sister taxon to) the remaining Testudinata, is sister to O. semitestacea (Li et al. 2008; Lyson et al. 2010). Following the study of Sterli and de la Fuente (2010), the following evolutionary changes have to be considered for the adductor chamber in turtles:

(1) An akinetic skull enabled by a suturing of the basitrabecular (basipterygoid) process and the pterygoid first evolved within - and not in the ground pattern - of Testudinata. The plesiomorphic condition of a basicranial kinetism still can be found in the basal-most turtles $P$. quenstedti and $O$. semitestacea. An additional plesiomorphic condition for both species (at least for $P$. quenstedti) may be the condition that the opisthotic is tightly sutured to the squamosal.
(2) Testudines and some advanced stem Testudines (Meiolania platycepts, Mongolochelys efremovi, Kallokibotion bajazidi) [together simplified discussed as 'advanced testudinates' herein; not to be confused with crown Testudines] show a complete reduction of the basitrabecular process. They also show the tendency to close the interpterygoid vacuity completely, a closure of the foramen nervi trigemini by the processus inferior parietalis, various kinds of temporal emarginations, caudad extensions of the crista supraoccipitalis, and the presence of an otic, or pterygoid trochlearis system (see Sterli and Joyce 2007). Sterli and de la Fuente (2010) argued for a strong evolutionary association of several of those characters in order to evolve a more effective bite performance in correlation with a growing "volume" of the adductor muscles.

Considering these anatomical features, muscle characters regarding the attachment sites of the adductor musculature (Table 2) are possibly only valuable for 'advanced testudinates'. The caudad extension of $\mathrm{m}$. adductor mandibulae externus Pars profundus (No. 19) over the Pars medialis (No. 17) (all codings: character 3) and the origin of the former on the supraoccipital (coding 1: character 33; coding 2+3: character 17) may be explained as relating to the emargination and/or caudal extension of the crista supraoccipitalis (Kilias 1957).

The secondary lateral braincase wall of turtles, formed by a laminar epipterygoid and/or an extended processus descendens parietalis, first occurs in Testudines. In the more basal Testudinata, the epipterygoid is quite small and the processus descendens parietalis rostrally does not extend over the anterior border of the prootic (Sterli and de la Fuente 2010). Consequently, the extension of $\mathrm{m}$. adductor mandibulae internus Pars pseudotemporalis principalis (No. 23) to the broad processus descendens parietalis (coding 1: character 90; coding 2: character 34) should be interpreted as a derived character of Testudines.

As mentioned above, a cavum tympani is absent in $O$. semitestacea ( $\mathrm{Li}$ et al. 2008). Although slightly concave in all early Testudinata, Sterli and de la Fuente (2010) determined that a particularly enlarged otic region first occurs just below the appearance of the Testudines clade. Muscle characters regarding the newly gained origination sites of the $\mathrm{mm}$. adductor mandibulae externus (No. 17, 21) et posterior (No. 29) portions to the quadrate or the prootic may be correlated to the acquisition of the enlarged otic region within Testudinata (coding 1: characters 51, 154; coding 3: character 23). Also the attachments of $\mathrm{m}$. adductor mandibulae externus Pars superficialis (No. 21) to the squamosal (coding 2-3: character $24)$, the latter of which has a changed relative position in the cranium, may be correlated to this feature. However, detailed observations of this skull region among Reptilia are needed to possibly detect autapomorphic arrangements of related bones already in the ground pattern of Testudinata. 
Several characters for turtles resulting from my character mapping concern the insertion sites of adductor muscles to the tendons and the lower jaw (Table 2). Compared to the remainder of the skull, no crucial evolutionary changes occurred in the arrangement of the posterior lower jaw bones of taxa on the stem linage of Testudines (see Joyce 2007). This could, on the one hand, speak in favour of the hypothesis that related muscle characters have been conserved since the first occurrence of Testudinata. However, first, O. semitestacea still had teeth on the dentary and bones related to the palate region $(\mathrm{Li}$ et al. 2008) and, as mentioned above, a basicranial kinesis of the turtle skull is still assumed to have been present in O. semitestacea and $P$. quenstedti. Both features may require different muscle arrangements to those reconstructed in my analysis. Moreover, it has often been mentioned in the literature that the trochlearis system of extant turtles might enable particular bite performances (e.g. Schumacher 1956b), which are correlated to topographical changes in the attachment of jaw musculature. It was also reported that the coronar aponeurosis (Schumacher's works: "external tendon"; Iordansky 1996) of extant turtles, which is correlated to the trochlearis system herein, differs markedly when compared to other reptiles. It extends far caudally, forms an internal cartilaginous or bony sesamoid structure (cartilago/os transiliens: Schumacher 1956b; Ray 1959), and may contain several sheets (Werneburg 2011).

As most jaw muscle characters defined herein seem to be dependent on the presence of the unique trochlearis system, the information they porvide for the phylogenetic origin of Testudinata within Amniota may be completely blurred. The trochlearis system as a whole includes the coronar aponeurosis containing one cartilago transiliens and one skeletal element. The skeletal elements, processus pterygoidei in pleurodires respectively processus otici in cryptodires, are built of nonhomologous structures (Joyce 2007), whereas the coronar aponeurosis is homologous among all turtle clades (Iordansky 1994). Given Joyce's (2007: Fig. 19) hypothesis of a double articulation of the coronar aponeurosis in the last common ancestor of Pleurodira and Cryptodira, the two cartilagines transiliens certainly resulting, not mentioned by the author, must be interpreted as non-homologous structures between both extant taxa. This double articulation of the coronar aponeurosis could have resulted in a different arrangement of jaw muscle structures in the last Testudines-ancestor when compared to the last common ancestor of Testudinata. Before the two distinct extant trochlearis mechanisms evolved, a previous rearrangement of jaw muscles may hence have occurred in concert with the acquisition of a simultanous pterygoid and otic related articulation. However, as will be shown below, gross anatomy of jaw muscles does not differ extensively among both extant turtle groups. This could indicate that a howsoever looking trochelaris system of the last common ancestor of Testudines already resulted in that particular jaw muscle anatomy, which was detected for extant turtles herein. However, this also could indicate that the double articulation already did not have much influence on jaw muscle gross anatomy. In this context, the absence of muscle data for early amniotes, which exhibited the plesiomorphic anapsid morphotype, makes it a difficult to generally declare the turtle jaw muscle anatomy as being derived. And, regardless of the elongated supraoccipital crest, it actually could resample most of the plesiomorphic condition, whereas saurian taxa could represent the more derived, temporal bar related jaw muscle arrangments.

The trochlearis systems and jaw muscle anatomy in extant taxa

Compared to Testudines, the two major extant turtle clades, Cryptodira and Pleurodira, are not obviously supported by jaw muscle characters (Table 2). It was a particular interest of this study to examine whether the attachments of the Partes pterygoidei of $\mathrm{m}$. adductor mandibulae internus (No. 26-28) correspond to the distinguishing architecture of the jaw adductor chamber. In Pleurodira, the $\mathrm{m}$. adductor mandibulae externus (No. 17-21) is bent around the processus trochlearis pterygoidei, whereas in Cryptodira the external jaw closing muscle is bent around the processus trochlearis otici (Schumacher 1956b; Gaffney and Meylan 1988).

Schumacher (1973) categorised the pterygoid-associated structures of the $\mathrm{m}$. adductor mandibulae internus differently in pleurodires and cryptodires (Fig. 1). However, based on the criteria of homology presented by Werneburg (2011), and contrary to Schumacher (1973), all muscular units of both taxa can be clearly homologised, including three Partes pterygoidei (No. 26-28) in both taxa (Fig. 1). In the Acctran optimisation of the preferred topology, Pleurodira show an autapomorphic shift of $\mathrm{m}$. adductor mandibulae internus Pars pterygoideus posterior (No. 27) to the lateral and/or to the dorsal face of the pterygoid (coding 1: character 136). In the same topology, a consensus character for Cryptodira is the expansion of the origin of $m$. adductor mandibulae externus Pars superficialis (No. 21) to the anterior face of the quadrate (coding 1: character 53; coding 23: character 48). Both characters may, with caution, be correlated with the differing trochlearis mechanisms in both taxa.

The m. intermandibularis (No. 31) of Pleurodira shows a rotation of its posterior fibres to a posteromediad direction when compared to the plesiomorphic condition (coding 1: character $181=$ coding $2+3$ : character 66 ). In addition, the Deltran optimisation of the preferred topology suggests that the m. intermandibularis (No. 31) in Pleurodira changed from a continuous transition with the m. constrictor colli complex (No. $40-43)$ to a superficial covering of the latter muscle anteriorly (coding 1: character $182=$ coding 2 , character 67 ). I hypothesise that both characters regarding the $\mathrm{m}$. intermandibularis (No. 31) anatomy might be correlated to the autapomorphic trochlearis mechanism in Pleurodira. The trochlearis system in that taxon is situated more anteroventrally when compared to 
cryptodires and, as such, it may mechanically be linked with $\mathrm{m}$. intermandibularis (No. 31). This muscle is situated nearby the trochlearis system and may need to stand particular forces in that taxon during jaw muscle activity.

The otic related trochlearis mechanism in Cryptodira, on the other hand, may have no effect on the anatomy of this mouth floor muscle - possibly balanced by the insertion of $\mathrm{m}$. intramandibularis (No. 25) into the fossa primordialis (Deltran for Cryptodira; coding 1: character $115=$ coding 3 : character 43). However, possibly independent, the $\mathrm{m}$. intramandibularis (No. 25) reportedly occurs only in a few cryptodire taxa (Iordansky 2008; Werneburg 2011) and the distribution of this character depends strongly on the underlying phylogenetic topology. Joyce (2007) mentioned the loss of the spenial bone without any reversals to be found in the lower jaw of Cryptodira and pelomedusoids. Hence, the resulting broader access to the primordial fossa may be correlated to the insertion of a m. intramandibularis (No. 25) in Cryptodira. However, to what degree trochlearis anatomy can be correlated to the arrangement of $\mathrm{m}$. intramandibularis (No. 25) in Testudines should be tested by mechanical studies in the future.

As mentioned above, Cryptodira is characterised by an expansion of the origin of $\mathrm{m}$. adductor mandibulae externus Pars superficialis (No. 21) to the anterior face of the quadrate, which could be correlated to the otic related trochlearis system in this taxon. The functional implications of the joint formed by processus trochlearis otici and cartilago/os transiliens may have an impact on the orientation of the ventral fibre arrangements in the dorsolaterally situated Pars superficialis (No. 21) towards an area ventrally to the course of the coronar aponeurosis.

Two additional points need to be mentioned that highlight the preliminary nature of my interpretations. (1) The proportions of the pterygoid portions (No. 26-28) were not coded herein due to insufficient data in the literature, but may contain some information to characterise both clades separately or even to interpret a possible, transitional, form as hypothesised by Joyce (2007) (see also Joyce and Sterli 2011). The proportions of the $\mathrm{m}$. adductor mandibulae externus portions as coded herein (No. 17-21, characters 2-8), however, did not contribute to this discussion. (2) As shown by Hertwig (2005), the distribution of muscle fibre types within muscular structures of the jaw apparatus may contain an enormous information content regarding functional adaptations in vertebrates. Although the muscular units related to the trochlearis systems do not contain much phylogenetic information in their gross anatomy, as coded herein, the distribution of muscle fibres inside the muscular structure may clearly distinguish both turtle taxa. Future studies should check my hypothesis that the muscle fibre distribution (e.g. slow-twitch oxidative type-I-fibres vs fasttwitch glycolytic type-II-fibres) differs particularly in the portions of the external jaw adductor (No. 17-21/22). Enabled by the different extent of their attachment areas (presence of processus trochlearis pterygoidei), the pterygoideus portions might differ only in their volume and fibre content as long as they have the same function. I maintain the same interpretive reservation regarding the functional morphology of all the muscular structures discussed in this paper.

\section{Conclusions}

Using the atomised definition of muscular units, traceable soft tissue characters were coded for phylogenetic analysis (character mapping). The concept of a plastic understanding of muscle anatomy and development ("lotus approach" of Werneburg 2011) served as the framework to understand the evolutionary changes of jaw muscle characters for the interpretation of muscle-bone interrelationship and their phylogenetic signal. Jaw muscle characters as defined in the presented study contain a high degree of phylogenetic noise on higher taxonomic level; however, at a "generic" level, characters may be informative.

Jaw muscle anatomy - as coded in the presented study does not contribute to the debate on turtle origin within Tetrapoda, and phylogenetic reconstructions with jaw muscle characters using PAUP* (Swofford 2003) did not resolve the interrelationship of the major turtle taxa. However, a character mapping was performed for a combined topology (Shaffer 2009; Iverson et al. 2007) of turtle interrelationship. Herein, Chelidae (Pleurodira) are subdivided into an Austalasian and a South American clade. Trionychia forms the sister taxon to all remaining cryptodires. Platysternon megacephalum forms the sister taxon to Testudinoidea; marine turtles, snapping turtles, and kinosternids form a monophyletic group.

Some clear correlations could be detected concerning the interrelationship of muscle attachment and skull anatomy; however, several muscle characters could not be correlated directly to skull shape. Internal anatomical features not documented herein, such as fibre orientation or musclefibre-type distribution, may contain information that could be correlated more directly to skull shape.

Using extant turtle taxa in broad-scale analysis of amniote phylogeny could result in a high degree of phylogenetic noise, as emarginations and related muscle characters evolved relatively recently. Although they have an anapsid morphotype, marine turtles do not represent the plesiomorphic skull and jaw muscle conditions of stem Testudines or of a possible anapsid ancestors.

The trochlearis system, which diagnoses the major extant turtle taxa (Pleurodira and Cryptodira) is hardly reflected by jaw muscle characters as defined herein. The general shape of jaw muscles remains constant among both groups. Fibre orientation of m. intermandibularis (No. 31) may, however, reflect the pleurodiran trochlearis system. In the future, 
mechanical studies may be useful to understand differences between the jaw mechanics among turtle taxa.

Acknowledgements Special thanks go to Marcelo R. Sánchez-Villagra and Walter G. Joyce for supporting this research and for discussion. In addition, I thank Joseph A. Corsini, Susan S. Evans, Marc E. H. Jones, Stefan T. Hertwig, Julio M. Hoyos, Wolfgang Maier, Christian Mitgutsch, Torsten M. Scheyer, Laura A. B. Wilson, anonymous reviewers, and particularly Rui Diogo for discussion, useful comments to the manuscript, and/or for providing specimens. But I am of course responsible for any remaining mistakes. The study was supported by the Swiss National Funds (No. 3100A0-116013 and No. 31003A 133032/1: granted to M.R.S.-V), by a Forschungskredit der Universität Zürich (No. 3772: granted to I.W.), by Deutsche Forschungsgemeinschaft (No. JO 928/11: granted to W.G.J.), and by a fund of the Japanese Society for the Promotion of Science (No. PE 11027: granted to I.W.).

\section{Appendix 1. Characters list 1 (phenetic approach; coding-1)}

The character list corresponds to Werneburg (2010).

\section{M. levator bulbi (No. 16)}

1 Structure is absent (0), present (1)

Ratio of $\mathbf{m}$. adductor mandibulae externus portions (No. 17-21)

The origin site of Pars ...

2 profundus (No. 19) extends more caudad than the origin site of Pars superficialis (No. 21): other way around (0), yes (1), +/- same (2).

3 profundus (No. 19) extends more caudad than the origin site of Pars medialis (No. 17): other way around (0), yes (1), +/- same (2).

4 medialis (No. 17) extends more caudad than the origin site of superficialis (No. 21): other way around (0), yes (1), +/- same (2).

5 profundus (No. 19) extends more rostrad than the origin site of superficialis (No. 21): other way around (0), yes (1), +/- same (2).

66 profundus (No.19) extends more rostrad than the origin site of medialis (No. 17): other way around (0), yes (1), +/- same (2).

7 medialis (No. 17) extends more rostrad than the origin site of superficialis (No. 21): other way around (0), yes (1), +/- same (2).

\section{Covering (from lateral view)}

8 Pars superficialis (No. 21) covers Pars medialis laterally: not or only a bit (0), mostly or completely (1).

\section{M. adductor mandibulae externus Pars medialis} (No. 17+18)

9 Structure is clearly separated from Pars superficialis (No. 21): no (0), yes (1).
M. adductor mandibulae externus Pars medialis (No. 17)

Origin of extends ...

10 to the rostral face of the quadrate: no (0), yes (1).

11 to the dorsal face of the quadrate: no (0), yes (1).

12 to the capsule of the jaw joint: no (0), yes (1).

13 to the squamosal: no (0), yes (1).

14 to the postorbital: no (0), yes (1).

15 to the quadratojugal: no (0), yes (1).

16 to the opisthotic: no (0), yes (1).

17 to the prootic: no (0), yes (1).

18 to the supraoccipital: no (0), yes (1).

19 to the parietal: no (0), yes (1).

Insertion extends ...

20 to the coronoid: no (0), yes, to the lateral border (1), yes, to the posterior border (2).

21 to the dorsal face of the surangular: no (0), yes (1).

22 to the medial face of the surangular: no (0), yes (1).

23 to the lateral face of the surangular: no (0), yes (1).

24 to the dentary: no (0), yes (1).

25 to the lateral face of the coronar aponeurosis: no (0), yes (1).

26 to the posterior face of the coronar aponeurosis: no (0), yes (1).

27 to the ventral face of the coronar aponeurosis: no (0), yes (1).

28 to the medial face of the coronar aponeurosis: no (0), yes (1).

29 to the anterior face of the coronar aponeurosis: no (0), yes (1).

30 to the dorsal face of the coronar aponeurosis: no (0), yes (1).

M. adductor mandibulae externus Pars medialis inferior (No. 18)

31 Structure is absent (0), present (1).

M. adductor mandibulae externus Pars profundus (No. 19)

Origin extends ...

32 to the parietal: no (0), yes (1).

33 to the supraoccipitale: no (0), yes (1).

34 via a tendinuous framework to the supraoccipital: no (0), yes (1).

35 to the postorbital: no (0), yes (1).

36 to the opisthotic: no (0), yes (1).

37 to the prootic: no (0), yes (1).

38 to the exoccipital: no (0), yes (1).

39 to the squamosal: no (0), yes (1).

Insertion extends ...

40 to the coronoid: no (0), yes (1). 
41 to the medial face of the coronar aponeurosis: no (0), yes (1).

42 to the dorsal face of the coronar aponeurosis: no (0), yes (1).

43 to the ventral face of the coronar aponeurosis: no (0), yes (1).

44 to the lateral face of the coronar aponeurosis: no (0), yes (1).

45 to the posterior face of the coronar aponeurosis: no (0), yes (1).

46 to the anterior face of the coronar aponeurosis: no (0), yes (1).

47 to the rictal plate: no (0), yes (1).

48 to the dentary: no (0), yes (1).

M. adductor mandibulae externus Pars profundus atypica (No. 20)

49 Structure is absent (0), present (1).

\section{M. adductor mandibulae externus Pars superficialis} (No. 21)

\section{Origin extends ...}

50 to the dorsal face of the quadratum: no (0), yes (1).

51 to the medial face of the quadratum: no (0), yes (1).

52 to the lateral face of the quadratum: no (0), yes (1).

53 to the anterior face of the quadratum: no (0), yes (1).

54 to the quadratojugal: no (0), yes (1).

55 to the lateral face of the squamosal: no (0), yes (1).

56 to the medial face of the squamosal: no (0), yes (1).

57 to the anterior face of the squamosal: no (0), yes (1).

58 to the dorsal face of the squamosal: no (0), yes (1).

59 to the ventral face of the squamosal: no (0), yes (1).

60 to the posterior face of the squamosal: no (0), yes (1).

61 to the postorbital: no (0), yes (1).

62 to the jugal: no (0), yes (1).

63 to the parietal: no (0), yes (1).

64 to the opisthotic: no (0), yes (1).

65 to the posterior face of the quadrate / basioccipital: no (0), yes (1).

66 to the prootic: no (0), yes (1).

Insertion extends ...

67 to the dentary: no (0), yes (1).

68 to the lateral face of the coronoid: no (0), yes (1).

69 to the posterior face of to the coronoid: no (0), yes (1).

70 to the dorsal face of the surangular: no (0), yes (1).

71 to the lateral face of the surangular: no (0), yes (1).

72 to the ventral face of the surangular: no (0), yes (1).

73 to the lateral face of the coronar aponeurosis: no (0), yes (1).

74 to the anterior face of the coronar aponeurosis: no (0), yes (1).
75 to the posterior face of the coronar aponeurosis: no (0), yes (1).

76 to the dorsal face of the coronar aponeurosis: no (0), yes (1).

77 to the ventral face of the coronar aponeurosis: no $(0)$, yes (1).

78 to the rictal plate: no (0), yes (1).

Cartilago transiliens within coronar aponeurosis ...

79 is absent (0), is present and has an articulation with: the pterygoid (1), with the quadratum / prootic (2).

\section{Coronar aponeurosis inserts ...}

80 to the dorsal face of the coronoid (process): no (0), yes (1).

81 to the medial face of the coronoid (process): no $(0)$, yes (1).

82 to the lateral face of the coronoid (process): no (0), yes (1).

83 to the dentary: no (0), yes (1).

84 to the surangular: no (0) yes (1).

85 to the prearticular: no (0), yes (1).

86 to the rictal plate: no (0), yes (1).

\section{M. zygomaticomandibularis (No. 22)}

87 Structure is absent (0), present (1).

M. adductor mandibulae internus Pars pseudotemporalis principalis (No. 23)

Position in relation to the ramus maxillaris nervi trigemini $\left(V_{2}\right)$

88 lateral (0), medial (1), posterolaterally pierced by nerve (2) Origin extends ...

89 to the parietal (not processus descendens part): no (0), yes (1).

90 to the processus descendens parietalis: no (0), yes (1).

91 to the epipterygoid (no epipterygoid in Pleurodira and Dermochelys coriacea sensu Joyce 2007): no (0), yes (1).

92 to the prootic: no (0), yes (1).

93 to the postorbital: no (0), yes (1).

94 to the frontal: no (0), yes (1).

95 to the interorbital septum: no (0), yes (1).

Insertion extends ...

96 to the subarticular aponeurosis: no (0), to the subarticular aponeurosis without $\mathrm{m}$. adductor mandibulae internus Partes pterygoidei (No. 26-28) (at least connected to their tendon) (1), to the subarticular aponeurosis together with Partes pterygoidei (No. 26-28) (2).

97 to the dorsal face of the cartilago Meckeli: no (0), yes (1).

98 to the medial face of the cartilago Meckeli: no (0), yes (1).

99 to the lateral face of the cartilago Meckeli: no (0), yes (1). 
100 to the ventral face of the cartilago Meckeli: no (0), yes (1).

101 to the surangular: no (0), yes (1).

102 to the dorsal face of the prearticular: no (0), yes (1).

103 to the medial face of the prearticular: no (0), yes (1).

104 to the Zwischensehne [with this also a m. intramandibularis (No. 25) is present]: no (0), yes (1).

105 to the dental: no (0), yes (1).

106 to the articular: no (0), yes (1).

107 to the dorsal face of the coronoid: no (0), yes (1).

108 to the ventral face of the coronoid: no (0), yes (1).

109 to the angular: no (0), yes (1).

M. adductor mandibulae internus Pars pseudotemporalis superficialis (No. 24)

Origin extends ...

110 to the parietal: no (0), yes (1).

Insertion extends ...

111 to the Zwischensehne [with this, also a m. intramandibularis (No. 25) is present]: no (0), yes (1).

112 to the subarticular aponeurosis: no (0), yes (1).

113 around the insertion of the coronar aponeurosis (coronar aponeurosis, cartilago transiliens, surangular, and / or coronoid process): no (0), yes (1).

M. adductor mandibulae internus Pars intramandibularis (No. 25)

Insertion extends ...

114 to the lateral face of the cartilago Meckeli: no (0), yes (1).

115 to the bones of fossa (canalis) primordialis: no (0), yes (1).

116 inserts also by a tendon to $f$ the fossa (canalis) primordialis: no (0), yes (1).

117 in a very long rostro-caudad extension: no (0), yes (1).

M. adductor mandibulae internus Pars pterygoideus dorsalis (No. 26)

Origin extends (next to the dorsal face of the pterygoid)

118 to the palatine: no (0), yes (1).

119 to the processus descendens parietalis: no (0), yes (1).

120 to the septum interorbitale: no (0), yes (1).

121 to the postorbital: no (0), yes (1).

122 to the jugal and maxilla: no (0), yes (1).

123 to the frontal: no (0), yes (1).

Muscle fibres insert (next to insertion to the subarticular aponeurosis) ...

124 to the articular: no (0), yes (1).

125 to the prearticular: no (0), yes (1).

126 to the cartilago Meckeli: no (0), yes (1).
127 to the capsule of the jaw joint: no (0), yes (1).

128 to the surangular: no (0), yes (1).

129 to the angular: no (0), yes (1).

130 to the coronoid: no (0), yes (1).

131 to the pterygoid tendon: no (0), yes (1).

132 via pterygoid tendon: to the internal tendon (as apo.pteDOR) (0) / separated insertion to the prearticular/ canalis primordialis (as apo.pteVEN) (1)

133 to the rictal plate: no (0), yes (1).

M. adductor mandibulae internus Pars pterygoideus posterior (No. 27)

Origin extends ...

134 to the quadrate: no (0), yes (1).

135 to the ventral face of or/and to the posterior face of the pterygoid: no (0), yes (1).

136 to the lateral face and/or to the dorsal face of the pterygoid: no (0), yes (1).

137 to the palatine: no (0), yes (1).

Insertion extends ...

138 to the articular (incl. retroarticular process): no (0), yes (1).

139 to the surangular: no (0), yes (1).

140 to prearticular: no (0), yes (1).

M. adductor mandibulae internus Pars pterygoideus ventralis (No. 28)

Origin extends (next to pterygoid) ...

141 to the palatine: no (0), yes (1).

Insertion extends ...

142 to the surangular: no (0), yes (1).

143 to the coronoid: no (0), yes (1).

144 to the angular: no (0), yes (1).

145 to the prearticular: no (0), yes (1).

146 to the articular: no (0), yes (1).

147 to the subarticular aponeurosis: no (0), yes (1).

148 to the pterygoid tendon: no (0), yes (1).

149 to the rictal plate: no (0), yes (1).

150 to the capsule of the jaw joint: no (0), yes (1).

M. adductor mandibulae posterior (Pars principalis) (No. 29)

Origin extends ...

151 Has two muscle heads in the origin area: no (0), yes (1). 152 to the quadrate: broadly at anterior surface $(0)$, restricted to the medial aspect of the anterior surface (1), ventrally (2)

153 to the pterygoid: no (0), yes (1)

154 to the prootic: no (0), broadly to the prootic (1), restricted to the lateral aspect of the prootic (2). 
155 to the lateral face of the parietal: no (0), yes (1).

156 to the quadratojugal: no (0), yes (1).

Insertion extends ...

157 to the prearticular: no (0), yes (1).

158 to the articular: no (0), yes (1).

159 to the angular: no (0), yes (1).

160 to the surangular: no (0), yes (1).

161 to the cartilago Meckeli: no (0), yes (1).

162 to the coronoid: no (0), yes (1).

163 to the coronar aponeurosis: no (0), yes (1).

164 via posterior aponeurosis (also "Sehnenspiegel") to surangular: no (0), yes (1).

165 via posterior aponeurosis to prearticular: no (0), yes (1).

166 via posterior aponeurosis to articular: no (0), yes (1).

167 via posterior aponeurosis to coronoid: no (0), yes (1).

\section{M. adductor mandibulae posterior Pars rostralis} (No. 29)

Origin extends (next to the anterior face of the prootic) ...

168 to the parietal: no (0), yes (1).

Insertion extends...

169 to the subarticular aponeurosis: no (0), yes (1).

170 to the coronoid: no (0), yes (1).

\section{Subarticular aponeurosis}

Insertion extends ...

171 to the dorsal face of the cartilago Meckeli: no (0), yes (1).

172 to the lateral face of the cartilago Meckeli: no (0), yes (1).

173 to the coronoid (process): no (0), yes (1).

174 to the dorsal face of the prearticular: no (0), yes (1).

175 to the medial face of the prearticular: no (0), yes (1).

176 to the articular: no (0), yes (1).

177 to the surangular: no (0), yes (1).

\section{M. intermandibularis (No. 31) ...}

178 reaches the symphysis of the dentals: no (0), yes (1).

179 a posterior trigonium is formed between $\mathrm{m}$. intermandibularis and constrictor colli complex (No. 40-43): no (0), yes (1).

180 contralateral muscles fuse in: a thin median raphe (0), a broad aponeurosis anteriorly (1), a broad aponeurosis posteriorly (2).

181 fibre course of the posterior part of the muscle around $45^{\circ}$ in posteromediad direction: no (0), yes (1).
182 covers anterior region of constrictor colli complex (No. 40-43) superficially: other way around (0), yes (1), no, homogen transition (2), muscles do not contact (only connected in area of median raphe (3), connected by connective tissue (4).

\section{M. depressor mandibulae (No. 45) ...}

183 has a bipinnated shape: no (0), yes (1).

Origin extends ...

184 originates with two muscle heads: no (0), yes (1).

185 to the posterior face of the squamosal: no (0), yes (1).

186 to the ventral face of the squamosal: no (0), yes (1).

187 to the lateral face of the squamosal: no (0), yes (1).

188 to the dorsal face of the squamosal: no (0), yes (1).

189 to the posterior face of the quadrate: no (0), yes (1).

190 to the lateral face of the quadrate: no (0), yes (1).

191 to the medial face of the quadrate: no (0), yes (1).

192 to the quadratojugal: no (0), yes (1).

193 to the opisthotic: no (0), yes (1).

194 to the jugal: no (0), yes (1).

195 to the cornu branchiale-II: no (0), yes (1).

\section{Insertion extends ...}

196 to the articular: no (0), yes (1).

197 to the angular: no (0), yes (1).

198 to the surangular: no (0), yes (1).

199 via tendon to the articular body: no (0), yes (1).

200 via tendon to the retroarticular process: no (0), yes (1).

201 via tendon to the angular: no (0), yes (1).

202 via tendon to the surangular: no (0), yes (1).

\section{Appendix 2. Character matrix 1 (phenetic approach; coding-1)}

Character matrix, including all information gathered from literature and own observations, including not applicable data. The character coding corresponds to Werneburg (2010) with few modifications in characters 9, 80, 89, 96, 104, 114-117, 125, and 198 for Caretta caretta and Lepidochelys kempii following new data by Jones et al. (2012). Multiple characters states for all characters $\mathrm{A}=(0,1), \mathrm{B}=(0,2), \mathrm{C}=(1,2), \mathrm{D}=(1,3)$, $\mathrm{E}=(2,3)$.

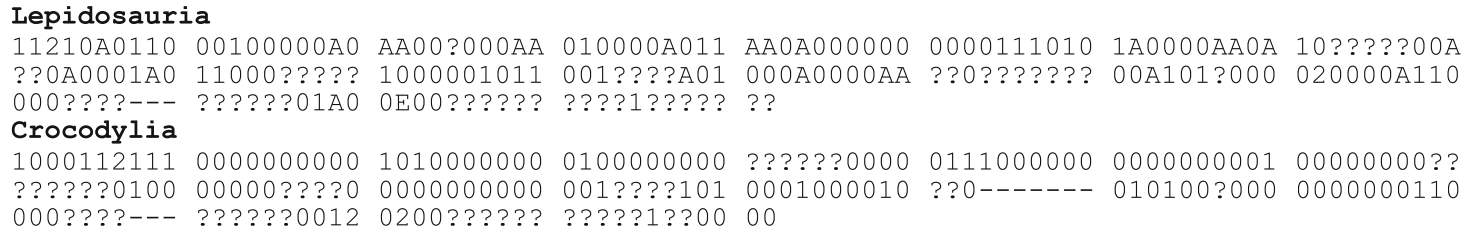




\section{Neornithes}

10A011C010 001000000? ????000000 0100000011 ??????0001 0100100000 00000011?1 1??????00? ??????0100 00000????? ???0000110 001----100 000?????? ??00000000 1???????? 000000???? ???????--- ?????0A10 0100 ????? ????1???? ??

\section{Amyda cartilaginea}

0110111011 1??0101000 $1010000000111000000111111 ? ? 00 ?$ ???0010100 0000000001 010000000? ??????1111 00??020000 $000000000-------0000000000000--0------0000101-001101001100$ $0000000--0001100$ ??? ??10??10?? ?0??0??000 00

Caretta caretta

0110210111 OOAOAOOOOA O000AAOAAA 0110000000 011000000A A0A10AA000 1110000??? ??A0000021 1111000111 O000A00010 1001000001 100111011A 0001111000 1A01101100 A000110110 A001001000 $000 A A A 0--$ ????????? 02011000?? ?A00000011 00

Chelodina longicollis

021011?001 O0A0000000 11100A0A0A 0110110100 000010A010 10A00A0AAA 0001000000 001AA00A11 A11AAA0101 -?0002???? O000AA???- ------AA0 000A0000A0 --00010010 ----- ?--- 010CA01100 OAA0000--- ??1110A111 1?0AA0A000 001001000000

\section{lonia mydas}

011????110 0000000002 ??1?010000 011000000001100000010001010000 1110000??? ??10000021 $11110001010000000010110000000------11$ A 0001111000110110110000001101011001000000 $0011110---$ ????????? ??01100000 000000001100

Chelonoidis denticulata

01102100111000000000 ??10?????? 0?1??????0 110000000100010100001000000001 ?100000021 ??01000111 $1100010000000000000------11 \mathrm{~A} 0000000000$ 110------ 1??????0?? 0?????1000 $0010000--000100001011000110$ ?? ?0??0??000 00

Chelonoidis nigra

0210210010000000000 ? ???0110000 0110000000000100000010010100001001000100 101000002? ??????0?01 0100020000 1??000000- -------11A 0000100100 0-0------- 00000001000100000100 $0000010--0000010$ ??? ??010000110000011001 00

Chelus fimbricatus

$00100200101010-1100110101111110010000100010100000000000010000010000000101000001$ ? ??01??0100-010020000 $0000000001010----1110000000000100-------$ ??????0??0012000100 $0010000--0000010111$ A???????? ??????0?? ??

Chelydra serpentina

0111010100001001000 ? 0000110100 0110000000 1000100000 A0AA001A00 1AA000100? ??1A000A21 $10100 A 0201$ OA1?A20000 $000000000-------1 ? 00000000000--0------0000001-00$ A101001100 $0000000--000 ? ? 00110000010 A A 00 \quad 000001000000$

Chrysemys picta

02100100?0 0010000000 ???1110000 011000000010001000001011000000 010000???? ????????2? ??????0101 $0000020000000100000 ?$ ???0101?00 0000000000--0------- ???????-?? 0101000000 0001 ?10--- ??????0100 03010?00?? ?0?00??000 00

Clemmys guttata

011??????0 001000000000101000000110000000100010000010110000001100001000001100002 ?

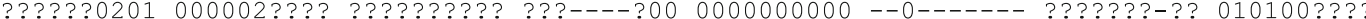
??????--- ?????0010 00??001000 00000??0?? ??

\section{Cuora amboinensis}

01122101 ?0 00100101000000000100011000000010001000001011000000 110000???? ????????2? $1100000201000002 ? ? ? ?$ ?????????-------?000000000000 0-0------- ???????-?? 0101000000 1000000--- ?????00?? ??0001?000 00??0??000 00

Dermochelys coriacea

1121000011 10101A0002 0100AAOAAO OA1000000A OAAOAA0000 1011010000 1110000001 ?111000000 $0000000000-10001 ? ? ? ? 01 ? 000000 ?$ ???----A00 0000110000 110------ 1000000100 AA010A0001 0000000 ?? $00000001 \mathrm{AO}$ OEOA1000?? ?A000111?? ??

Dogania subplana

0110110??0 010000000C 1011000000 01111110011101001000101101000001010001100010100021 $1111101 ? 110011020000000000000-\ldots-----1001100000001$--0------- ----- ?--- 0?????0000 $0010000---0011110$ ??? ???0????00 000001000100

Emydura macquarii

$02102100000000000002 \quad 1 ? 0000000001101000000110000000 \quad 100-0100111011110000 \quad 0000011011$ $1111100 ? 11-01101000001000 ? 000-------1000001100000110-------00000001000102001100$ 000 ???:-- ???1??0??? ??10001000 000001000000

Emydura subglobosa

$02102100100000000000001100000001100000010110000001000-01010000101000000010001011$ $1100000101-110010000000000000-------1000000000000110-------$ ???????0? 0102100001 $1000000--0000010110$ 1D00101100 000000001? ??

Emys orbicularis

0110121000 001001000A 00A0110A00 01100A0000 AAAAA00001 A0A1000000 1100000A0? ??1A000021 $11111002010000020010011000 ? ? ?------1000000001000--0------1000000-01$ 010A00?A00 $0001010---$ ?????0A10 0300101000 00000??0?? ?

Eretmochelys imbricata

01102101111000100000 ??10?1???? 0110000000000010000000010100001000001001 ?100000021 $00010 ? 01110000010000000000000-------1010000100000--0-------1 ? ? ? ? ? ?-? ? 1101001100$ 0010000--- 0001000110 0?00100000 00??0??000 00

Graptemys geographica

01102100110000000000 ???0110000 01110100001000100000100001000000000000000010100021 $1111100 ? 01000002$ ???? $000000000------1000000001000--0------1000000-010102000000$ $0000010--0101100$ ??? ???0001000 000000000100

Graptemys pseudogeographica

0????????1 $001000000 ?$ ?????????? 011000000000001000001011000000 010000???? ??11????2?

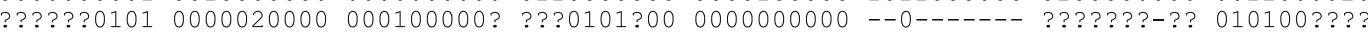
?????? --- ??????0?? ????????? ??????0?? ??

Hydromedusa tectifera

0210111001000000000000101100000110110000 ????????00 1000010001 0000000000 00?????011 $1111100111-011021000000000000-------0101000100000--0-------------?---0101-01001$ $0010000---1001100$ ??? ??00111001 001000000100 
Kinosternon leucostomum

0????????1 0010000110000000100101110000001110100000101101010011000010011011000021 11000 ?0201 000002 ???? ???0??????------?00 $0000000000--1-----1$ ???????-?? 0101000100 $0000010---$ ??????00?? ???????? ????0? 0?? ??

Kinosternon scorpioides

0110110??1 0010000110 $00000010010111000000111010000010110101001100001001101100002 ?$

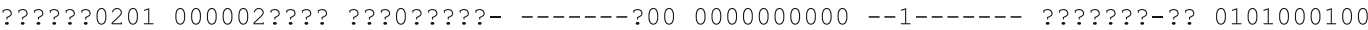
$0000010---$ ??????00?? ??000?1000 00??0??000 00

Lepidochelys kempii

0110??0?01 00000000000100000000011000000010000000000011000100 110101???? ??00000021 11????0101 0000000000 000100000? ???1110101 0000100000 1?0?????? 1000000100 1102001100 0000000 ??? ?????01?0 02??111000 00000???? 00

Lissemys punctata

0110??0?11 00000000000100000000011000000010000000000011000101 110101???? ??00000021 11????01110000020000 000?00000- -------101 0000000000 1-0------- 10000001001102001100 $0000000--$ ??????01?0 02??111000 00000??0?? 00

Macrochelys temminckii

01101100?1 010000000C 1011000000 01111110011101001000101001000000010001100010100021 11AAA01111 $0011020000000000000--------A 00$ A10000000A --0------- ???????-?? 0000001100 00A0001001 0011110110 ?310001100 0000010001 A0

Malaclemys terrapin litoralis

01102101?1 0000000000 ???0010000 0010011000 1011000000 1000010000 0000000??0 101000012?

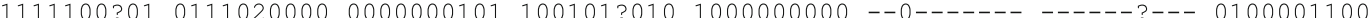
$0000000--00111100000201100101000101100000$

\section{Mauremys caspica}

011??????1 0010000000001111100001100000001001100000101100000010100010000011000021

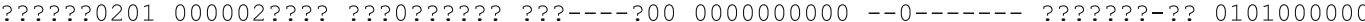
000??10--- ?????00?? ??001?1000 00??0??000 00

\section{Mauremys rivulata}

0110??01?1 $0010000000 \quad 0010100000 \quad 0110000000100010000010110000001100000000 \quad 0011000021$ $110 ? 0 ? 0201000002 ? ? ? ?$ ???0?????? ???----?00 0000000000--0------- ???????-?? 010200???? ??????--- 11010100 ?? ??001?10?? ?0??0??000 00

\section{Mesoclemmys nasuta}

0??????1?1 0000000000 ???0110000 $011001000011100000000001010000010000000 ?$ ???????12? $1111100 ? 010000021010001000100 ? ? ? ?---1100000100100 \quad 0-0------00010101000102001100$ 0010000--- 0000010??? ??0001000 00000??0?? ??

Pelodiscus sinensis

0010?10101 00?00??000 $000000100001100000000100100000101-? ? ? ? ? ? 001101 ? ? ? 1$ ?????1?011

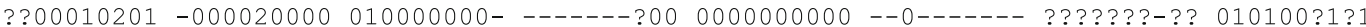
00 ?0000--- ????? 01 ? 00000 ?1000 00??0??0?? ??

Pelomedusa subrufa

0110110011 01100A000C 1011A0000A 0111AAA001 11A1A0AA00 10AA0A0000 0A0A00AAA? ??1AA00021 11AAA012A1 000A020000 000000000- ------AA0 AA00000001 0-00010100 1010000-00 0A01001100 $0000000--0011110$ ??? ??1A011000 000001010101

Pelusios niger

0210020001010000000000101100000110000001010100000010010100001100000100001000101 ? $1110100101-000010000010000000-------0101011100001110-------1010000110010110 ? 100$ $1010000--100101001$ ? 0300011000001001000100

Pelusios sinuatus

$021021000100 ? 00 ? 0000 \quad 0000 ? 01 ? 00 \quad 011000000001001000101011010 ? 0101010 ? 0000 \quad 0000000111$ ?????10101 -000020000 $000001000-------? 000000000000-0-------$ ???????-?? 1101A00000 $0000100---$ ????? 0110 13??????? ???????? ??

Pelusios subniger

0210210001000000000 ? ???0110000 01100010001000000000100101000010100001001010001011 $1111000101-100020000$ 0??000000- ------?00 $0000000000--0-----0000110-000001000001$ 000 ???0--- ?????0??? ??01010000 10100100?? ??

Platysternon megacephalum

0????????1 000000000? ???0110000 01100010001000000000100101000010100001001010001011 $1111000 ? 01-1000200000 ? ? 000000-------? 000000000000--0------0000110-000001000001$ 000 ???0--- ??????0??? ???1010000 10100100?? ??

\section{Podocnemis expansa}

01100100110000000000000011100001100000001110000000000001000010000001000000100021 $111110010100000200000000000001100101 ? 1000000001001--0------1010000-010001001000$ 0000100--- 0011111??? ??00100010 00000000?1 ?0

Podocnemis unifilis

$011001001100 A 000000$ ? ???0110000 01110000011010000001000001000000010001000010001011 $1111000101-100020000000000000-------? 000000000000--001001010100101-000001000100$ 000000001000000110101101010000001100000100

Sternotherus odoratus

0???????? 000000000 ? ???0110000 0111000000101000000100000100000001000100001000101 ? $1111000 ? 01-100020000000000000-------? 000000000000--101001010100101-000001000100$ 00000000100000010 ??? ?3?1010000 001100000100

Terrapene carolina

0????????1 $001000011000000010010111000000111000000 ?$ ???1000000 00000000000011000121 ?????:0110 $0000020000000000000 ?$ ???----?00 0000100000 --1------ ???????-?? 0101000100 $0000010---$ ??????00?? ????????? ????????? ??

Testudo graeca

01102100110010100001 ??101????? 01101000001100000010 A0A00A0A00 000000000A ?AAA000A20

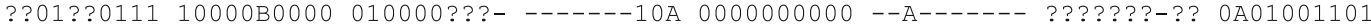
$00 A 111$ ?--- ???1??00?? ??000?11?? ?0??0???00 00

Trachemys scripta

0210210011 00A0100000 A??0100000 0110000000 1001100001 A01A010000 0A0000A001 10AA00002? 11110000A1 OA00020000 000000000- ------1A0 0000000000 1100000000 0000001000 010A00?100 00A0000--- 00010100101400000011000001100000 
Trachemys terrapen

0????????1 0010000000 ???0110000 011000000010001000001011000000 110000???? ??11000021

??????0?01 00000200000101000001 1001?0??00 0000000000--00000000 ??????-?? 0101000000

00 ? ?10--- ?????0A10 03??????? ???????? ??

\section{Appendix 3. Characters list 2 (multiple character approach; coding-2 and -3 )}

Characters are derived from Appendix 1. Numbers in square brackets indicate the corresponding characters in Appendix 1.

1-9 Characters 1-9 correspond to characters 1-9 of Appendix 1.

\section{M. adductor mandibulae externus Pars medialis (No. 17)}

10 Origin extends to the quadrate (0), capsule of the jaw joint (1), squamosal (2), postorbital (3), quadratojugal (4), opisthotic (5), prootic (6), supraoccipital (7), parietal (8). [10-19]

11 Origin extends the rostral face (0) or to the dorsal (1) of the quadrate. [10-11]

12 Insertion extends to the coronoid (0), surangular (1), dentary (2), coronar aponeurosis (3). [20-30]

13 Insertion extends to the lateral border (0), to the posterior border (1) of the coronoid. [20/1,20/2]

14 Insertion extends to the dorsal face (0), medial face (1), lateral face (1) of the surangular. [21-23]

15 Insertion extends to the lateral face (0), posterior face (1), ventral face (2), medial face (3), anterior face (4), dorsal face (5) of the coronar aponeurosis. [25-30]

\section{M. adductor mandibulae externus Pars medialis inferior} (No. 18)

16. Structure is absent (0), present (1). [31]

\section{M. adductor mandibulae externus Pars profundus} (No. 19)

17. Origin extends to the parietal (0), supraoccipital (1), postorbital (2), opisthotic (3), prootic (4), exoccipital (5), squamosal (6). [32-39]

18. Originates directly (0), via a tendinuous framework (1) from the supraoccipital. [33-34]

19. Insertion extends to the coronoid (0), coronar aponeurosis (1), rictal plate (2), the dentary (3). [40-48]

20. Insertion extends to the medial face (0), dorsal face (1), ventral face (2), lateral face (3), posterior face (4), anterior face (5) of the coronar aponeurosis. [41-46]

\section{M. adductor mandibulae externus Pars profundus} atypica (No. 20)

21. Structure is absent (0), present (1). [49]
M. adductor mandibulae externus Pars superficialis (No. 21)

22. Origin extends to the quadratum (0), quadratojugal (1), squamosal (2), postorbital (3), jugal (4), parietal (5), opisthotic (6), prootic (7). [50-66]

23. Origin extends to the dorsal (0), medial (1), lateral (2), anterior (3) face of the quadrate, or to the posterior face of the quadrate and/or basioccipital (4). [50-53,65]

24. Origin extends to the lateral (0), medial (1), anterior (2), dorsal (3), ventral (4), posterior (5) face of the squamosal. [55-60]

25. Insertion extends to the dentary (0), coronoid (1), surangular (2), coronar aponeurosis (3), rictal plate (4). [67-78]

26. Insertion extends to the lateral (0), posterior (1) face of to the coronoid. [68-69]

27. Insertion extends to the dorsal (0), lateral (1), ventral (2) face of the surangular. [70-72]

28. Insertion extends to the lateral (0), anterior (1), posterior (2), dorsal (3), ventral (4) face of the coronar aponeurosis. [73-77]

\section{Cartilago transiliens within coronar aponeurosis ...}

29. has an articulation with: the pterygoid (0), with the quadratum / prootic (1). [79]

Coronar aponeurosis inserts ...

30 . to the coronoid (process) (0), dentary (1), surangular (2), prearticular (3), rictal plate (4). [80-86]

31 . to the dorsal (0), medial (1), lateral (2)face of the coronoid (process). [80-82]

\section{M. zygomaticomandibularis (No. 22)}

32. Structure is absent (0), present (1). [87]

M. adductor mandibulae internus Pars pseudotemporalis principalis (No. 23)

33. Position in relation to the ramus maxillaris nervi trigemini $\left(\mathrm{V}_{2}\right)$ : lateral $(0)$, medial (1), posterolaterally pierced by the nerve (2). [88]

34. Origin extends to the parietal (not processus descendens part) (0), processus descendens parietalis (1), epipterygoid (no epipterygoid in Pleurodira and Dermochelys coriacea sensu Joyce 2007) (2), prootic (3), postorbital (4), frontal (5), interorbital septum (6). [8995] 
35. Insertion extends to the subarticular aponeurosis (0), cartilago Meckeli (1), surangular (2), prearticular (3), Zwischensehne with this also a $\mathrm{m}$. intramandibularis (No. 25) is present] (4), dental (5), articular (6), coronoid (7), angular (8). [96109]

36. Insertion extends to the subarticular aponeurosis without $\mathrm{m}$. adductor mandibulae internus Partes pterygoidei (No. 26-28) (at least connected to their tendon) (0), to the subarticular aponeurosis together with Partes pterygoidei (No. 26-28) (1). [96/1, 96/2]

37. Insertion extends to the dorsal face (0), medial (1), lateral (2), ventral (3) face of the cartilago Meckeli. [97-100]

38. Insertion extends to the dorsal (0), medial (1) face of the prearticular. [102-103]

39. Insertion extends to the dorsal (0), ventral (1) face of the coronoid. [107-108]

M. adductor mandibulae internus Pars pseudotemporalis superficialis (No. 24)

40. Origin extends to the parietal: no (0), yes (1). [110]

41. Insertion extends to the Zwischensehne [with this, also a m. intramandibularis (No. 25) is present] (0), subarticular aponeurosis (1), around the insertion of the coronar aponeurosis (coronar aponeurosis, cartilago transiliens, surangular, and / or coronoid process) (2). [111-113]

M. adductor mandibulae internus Pars intramandibularis (No. 25)

42. Insertion extends to the lateral face of the cartilago Meckeli (0), to the fossa (canalis) primordialis (1), in a very long rostro-caudad extension (2). [114-117]

43. Insertion extends with a direct attachment to the bones of fossa (canalis) primordialis $(0)$, by a tendon to that fossa (1). [115-116]

M. adductor mandibulae internus Pars pterygoideus dorsalis (No. 26)

Origin extends (next to the dorsal face of the pterygoid) ...

44. Origin extends to the palatine $(0)$, processus descendens parietalis (1), septum interorbitale (2), postorbital (3), jugal and maxilla (4), the frontal (5). [118-123]

Muscle fibres insert (next to insertion to the subarticular aponeurosis) ...

45. to the articular (0), prearticular (1), cartilago Meckeli (2), capsule of the jaw joint (3), surangular (4), angular
(5), coronoid (6), pterygoid tendon (7), rictal plate (8). [124-131, 133]

46. Inserts via pterygoid tendon: to the internal tendon (as apo.pteDOR) (0) / separated insertion to the prearticular/canalis primordialis (as apo.pteVEN) (1). [132]

M. adductor mandibulae internus Pars pterygoideus posterior (No. 27)

47. Origin extends to the quadrate (0), pterygoid (1), palatine (2). [134-137]

48. Origin extends to the ventral face of or/and to the posterior face (0), lateral face and/or to the dorsal face of the pterygoid (1). [135-136]

49. Insertion extends to the articular (incl. retroarticular process) (0), surangular (1), prearticular (2). [138-140]

M. adductor mandibulae internus Pars pterygoideus ventralis (No. 28)

50. Origin extends only to the pterygoid (0), also to the palatine (1). [141]

51. Insertion extends to the surangular (0), coronoid (1), angular (2), prearticular (3), articular (4), subarticular aponeurosis (5), pterygoid tendon (6), rictal plate (7), capsule of the jaw joint (8). [142-150]

\section{M. adductor mandibulae posterior (Pars principalis)} (No. 29)

52. Has two muscle heads in the origin area: no (0), yes (1). [151]

53. Origin extends to the quadrate (0), pterygoid (1), prootic (2), lateral face of the parietal (3), quadratojugal (4). [152-156]

54. Origin extends to the quadrate: broadly at anterior surface (0), restricted to the medial aspect of the anterior surface (1), ventrally (2). [152]

55. Origin extends broadly to the prootic $(0)$, restricted to the lateral aspect of the prootic (1). [154/1, 154/2]

56. Insertion extends to the prearticular (0), articular (1), angular (2), surangular (3), cartilago Meckeli (4), coronoid (5), coronar aponeurosis (6), inserts via posterior aponeurosis (also "Sehnenspiegel") (7). [157-167]

57. The posterior aponeurosis (also "Sehnenspiegel") inserts to surangular (0), prearticular (1), articular (2), coronoid (3). [164-167]

\section{M. adductor mandibulae posterior Pars rostralis} (No. 29)

58. Origin extends to the anterior face of the prootic $(0)$, also to the parietal (1). [168]

59. Insertion extends to the subarticular aponeurosis $(0)$, coronoid (1). [169-170] 


\section{Subarticular aponeurosis}

60. Insertion extends to the cartilago Meckeli (0), coronoid (process) (1), prearticular (2), articular (3), surangular (4). [171-177]

61. Insertion extends to the dorsal (0), lateral (1) face of the cartilago Meckeli. [171-172]

62. Insertion extends to the dorsal (0), medial (1) face of the prearticular. [174-175]

\section{M. intermandibularis (No. 31) ...}

63. reaches the symphysis of the dentals: no (0), yes (1). [178]

64. a posterior trigonium is formed between $\mathrm{m}$. intermandibularis and constrictor colli complex (No. 40-43): no (0), yes (1). [179]

65. contralateral muscles fuse in: a thin median raphe $(0)$, a broad aponeurosis anteriorly (1), a broad aponeurosis posteriorly (2). [180]

66. fibre course of the posterior part of the muscle around $45^{\circ}$ in posteromediad direction: no (0), yes (1). [181]

67. covers anterior region of constrictor colli complex (No. 40-43) superficially: other way around (0), yes (1), no, homogen transition (2), muscles do not contact (only connected in area of median raphe (3), connected by connective tissue (4). [182]

\section{M. depressor mandibulae (No. 45) ...}

68. has a bipinnated shape: no (0), yes (1). [183]

69. originates with two muscle heads: no (0), yes (1). [184]

70. Origin extends to the squamosal (0), quadrate (1), quadratojugal (2), opisthotic (3), jugal (4), cornu branchiale-II (5). [185-195]

71. Origin extends to the posterior (0), ventral (1), lateral (2), dorsal (3) face of the squamosal. [185-188]

72. Origin extends to the posterior (0), lateral (1), medial (2) face of the quadrate. [189-191]

73. Insertion extends direct to the articular (0), angular (1), or surangular (2), or via a tendon to the lower jaw (3). [196-202]

74. Insertion extends via a tendon to the articular body (0), retroarticular process (1), angular (2), surangular (3). [199-202]

\section{Appendix 4. Characters matrix 2 (for coding-2 and -3)}

Multiple character states are shown as a letters. For coding-2, all multiple states (numbers) were used. For coding-3, the letters were used. Multiple characters are coded as follows (bold number $=$ character, letter $=$ character with multiple states, number in brackets = multiple character states coded by the letter): $3 \mathrm{~A}=$ $(0,1) ; 6 \mathrm{~A}=(0,1) ; 7 \mathrm{~A}=(1,2) ; \mathbf{1 0} \mathrm{A}=(0,1) ; \mathrm{B}=(0,1,2,5)$,
$\mathrm{C}=(0,2), \quad \mathrm{D}=(0,2,4), \quad \mathrm{E}=(0,2,5,6), \quad \mathrm{F}=(0,2,7,8), \mathrm{G}=(0,4)$, $\mathrm{H}=(0,4,6), \mathrm{K}=(2,4), \mathrm{M}=(2,4,5), \quad \mathrm{N}=(2,5), \quad \mathrm{P}=(2,6), \quad \mathrm{Q}=$ $(2,8) ; 11 \mathrm{~A}=(0,1) ; 12 \mathrm{~A}=(0,1), \mathrm{B}=(0,1,2), \mathrm{C}=(0,1,3)$, $\mathrm{D}=(0,3), \mathrm{E}=(1,3), \mathrm{F}=(2,3) ; 13 \mathrm{~A}=(0,1) ; 14 \mathrm{~A}=(0,1) ; \mathrm{B}=$ $(0,1,2), C=(0,2) ; 15 A=(0,1), B=(0,1,2), C=(0,1,2,3,4,5)$, $\mathrm{D}=(0,1,3), \quad \mathrm{E}=(0,1,3,4), \quad \mathrm{F}=(0,1,3,4,5), \quad \mathrm{G}=(0,5), \quad \mathrm{H}=$ $(1,3,5), \quad K=(2,5), \quad M=(4,5) ; \quad 17 \quad A=(0,1), \quad B=(0,1,2), \quad C=$ $(0,1,2,3), \quad D=(0,1,2,3,4), \quad E=(0,1,2,3,5), \quad F=(0,1,3), \quad G=$ $(0,1,4), H=(0,4,6), K=(0,6), M=(1,3,4), N=(1,5) ; 18 \mathrm{~A}=$ $(0,1) ; 19 \mathrm{~A}=(0,1), \mathrm{B}=(0,1,2), \mathrm{C}=(0,1,2,3), \mathrm{D}=(1,2) ; \mathbf{2 0}$ $A=(0,1), \quad B=(0,1,2), \quad C=(0,1,2,3,4), \quad D=(0,1,2,3,4,5), \quad E=$ $(0,1,2,4), \quad \mathrm{F}=(0,1,3), \mathrm{G}=(0,1,5), \mathrm{H}=(0,2), \mathrm{K}=(0,2,3), \mathrm{M}=$ $(0,3,4), \mathrm{N}=(0,4), \mathrm{P}=(1,2), \mathrm{Q}=(1,2,4,5), \mathrm{R}=(1,3), \mathrm{S}=(1,4)$; $22 \mathrm{~A}=(0,1), \mathrm{B}=(0,1,2), \mathrm{C}=(0,1,2,3), \mathrm{D}=(0,1,2,3,4), \mathrm{E}=$ $(0,1,2,3,4,5), \quad F=(0,1,2,3,4,6,7), \quad G=(0,1,2,3,5), \quad H=$ $(0,1,2,4), \quad \mathrm{K}=(0,1,2,4,6), \mathrm{M}=(0,1,3,4), \mathrm{N}=(0,1,3,5), \quad \mathrm{P}=$ $(0,1,4), \quad Q=(0,2), \quad \mathrm{R}=(0,2,3,4,5), \quad \mathrm{S}=(0,2,3,5,6,7), \quad \mathrm{T}=$ $(0,2,5), \quad U=(0,2,6), \quad V=(0,3,4), \quad W=(0,5,6,7), \quad X=(1,2,3)$, $\mathrm{Y}=(1,2,4), \quad \mathrm{Z}=(2,3), \mathrm{a}=(2,3,4), \quad \mathrm{b}=(2,5) ; 23 \mathrm{~A}=(0,1,3)$, $\mathrm{B}=(0,2), \quad \mathrm{C}=(0,4), \quad \mathrm{D}=(1,3), \quad \mathrm{E}=(1,4), \quad \mathrm{F}=(2,3) ; 24 \mathrm{~A}=$ $(0,1,2,4), \quad B=(1,2), \quad C=(1,3), \quad D=(1,3,4,5), \quad E=(1,4,5), \quad F=$ $(1,5), \quad G=(2,3) ; 25 \quad A=(0,1,2), \quad B=(0,1,3), \quad C=(0,2), \quad D=$ $(0,2,3), \quad E=(0,3), \quad F=(0,3,4), \quad G=(1,2), \quad H=(1,2,3), \quad K=$ $(1,3), \quad \mathrm{M}=(2,3), \mathrm{N}=(2,4), \mathrm{P}=(3,4) ; 26 \mathrm{~A}=(0,1) ; 27 \mathrm{~A}=$ $(0,1), \quad B=(0,2) ; 28 \mathrm{~A}=(0,1), \quad B=(0,1,2), \quad C=(0,2), \quad D=$ $(0,4), \quad \mathrm{E}=(3,4) ; 30 \mathrm{~A}=(0,1,2), \quad \mathrm{B}=(0,1,2,3), \quad \mathrm{C}=$ $(0,1,2,3,4), \quad \mathrm{D}=(0,1,3), \mathrm{E}=(0,1,4), \mathrm{F}=(0,2) ; 31 \mathrm{~A}=(0,1)$, $\mathrm{B}=(0,1,2), \mathrm{C}=(1,2) ; 34 \mathrm{~A}=(0,1), \mathrm{B}=(0,1,2), \mathrm{C}=(0,1,2,3)$, $\mathrm{D}=(0,1,3), \quad \mathrm{E}=(0,1,4,5), \mathrm{F}=(0,1,5), \mathrm{G}=(0,1,6), \mathrm{H}=(0,2,3)$, $\mathrm{K}=(1,3), \quad \mathrm{M}=(1,3,4), \quad \mathrm{N}=(1,3,4,5), \quad \mathrm{P}=(1,3,4,6) ; 35 \mathrm{~A}=$ $(0,1), \quad B=(0,1,3), \quad C=(0,1,3,7), \quad D=(0,2), \quad E=(0,3), \quad F=$ $(0,3,4), \quad \mathrm{G}=(0,4), \mathrm{H}=(0,5,6), \mathrm{K}=(0,6), \mathrm{M}=(0,7), \quad \mathrm{N}=$ $(1,2,3), \quad \mathrm{P}=(1,2,4), \mathrm{Q}=(2,7,8), \mathrm{R}=(7,8) ; 37 \mathrm{~A}=(0,2) ; 38$ $\mathrm{A}=(0,1) ; 42 \mathrm{~A}=(0,1), \mathrm{B}=(1,2) ; 43 \mathrm{~A}=(0,1) ; 44 \mathrm{~A}=(0,1)$; $\mathrm{B}=(0,1,2), \mathrm{C}=(0,1,3,4), \mathrm{D}=(0,2), \mathrm{E}=(0,3,4), \mathrm{F}=(1,3), \mathrm{G}=$ $(1,5) ; 45 \mathrm{~A}=(0,1,2,3,7), \mathrm{B}=(0,1,2,6,7), \mathrm{C}=(0,1,7), \mathrm{D}=$ $(0,5), \mathrm{E}=(0,5,6), \mathrm{F}=(1,2,7), \mathrm{G}=(1,4), \mathrm{H}=(1,7), \mathrm{K}=(1,8)$, $\mathrm{M}=(3,6) ; 46 \mathrm{~A}=(0,1) ; 47 \mathrm{~A}=(0,1,2) ; 49 \mathrm{~A}=(0,2) ; 50 \mathrm{~A}=$ $(0,1) ; 51 \mathrm{~A}=(0,2), \mathrm{B}=(0,3,5), \mathrm{C}=(1,2,4), \mathrm{D}=(1,6,7), \mathrm{E}=$ $(1,8), \mathrm{F}=(2,4,6), \mathrm{G}=(3,4), \mathrm{H}=(3,4,6,7), \mathrm{K}=(3,4,6,8), \mathrm{M}=$ $(3,5) ; 52 \mathrm{~A}=(0,1), 54 \mathrm{~A}=(0,1), 55 \mathrm{~A}=(0,1) ; 56 \mathrm{~A}=(0,1)$, $\mathrm{B}=(0,1,2), \quad \mathrm{C}=(0,1,3,6,7), \quad \mathrm{D}=(0,1,5,6), \quad \mathrm{E}=(0,1,6,7), \quad \mathrm{F}=$ $(0,3,6), \mathrm{G}=(0,7), \mathrm{H}=(1,2), \mathrm{K}=(1,3), \mathrm{M}=(1,4,6), \mathrm{N}=(1,6)$, $\mathrm{P}=(1,7), \quad \mathrm{Q}=(3,4), \mathrm{R}=(6,7) ; 57 \mathrm{~A}=(0,1,2), \mathrm{B}=(0,2) ; \quad \mathbf{6 0}$ $A=(0,2), \quad B=(0,2,3), \quad C=(1,2,3), \quad D=(1,2,3,4), \quad E=(1,2,4)$, $\mathrm{F}=(2,3), \quad \mathrm{G}=(3,4) ; 61 \mathrm{~A}=(0,1) ; 62 \mathrm{~A}=(0,1) ; 63 \mathrm{~A}=(0,1)$; $64 \mathrm{~A}=(0,1) ; 66 \mathrm{~A}=(0,1) ; 67 \mathrm{~A}=(1,3), \mathrm{B}=(2,3) ; 69 \mathrm{~A}=$ $(0,1) ; 70 \mathrm{~A}=(0,1), \mathrm{B}=(0,1,3), \quad \mathrm{C}=(0,1,4), \quad \mathrm{D}=(0,2), \quad \mathrm{E}=$ $(0,3), \quad F=(0,3,4) ; 71 \quad A=(0,1,2), \quad B=(0,2), \quad C=(0,2,3), \quad D=$ $(0,3), \quad E=(1,2), \quad F=(2,3), 72 \quad A=(0,1) ; 73 \quad A=(0,1), \quad B=$ $(0,3), C=(0,1,2), D=(0,1,3), E=(0,2,3), F=(0,3) ; 74 . \quad A=$ $(0,1), \mathrm{B}=(1,2), \mathrm{C}=(1,3)$ 
Lepidosauria

$11210 \mathrm{~A} 0110$
Crocodylia

1000112110

$-\mathrm{E} ? \mathrm{AMOH}-\mathrm{AF}$

$O A-A A-A ? \times F$

2??DE? ?? ? 0

$\mathrm{C} 002-\mathrm{B} ?--$ ?

01?C-00--? OAG-2-0-??

10A011A012

Amyda_cartilaginea

011011101H A1?C-1A0AD

Caretta_caretta

011021011G 0D0-F0A01P

Chelodina_longicollis

021011?00̄ OE-BHOROD4

Chelonia_mydas

011????11- -C1210A01P

Chelonoidis_denticulata

0110210010 A1-2?0101A 0C012-B-1F

Chelonoidis_nigra

021021001 - -3 ??A0A Chelus fimbricatus

001002001E 1C0CC0N01

Chelydra_serpentina

$011101010 \mathrm{P}$-3?-D0A010

Chrysemys_picta

02100100?2 -F??A0A010

Clemmys guttata

011??????2 -E-200A010

Cuora amboinensis

$01122 \overline{1} 01$ ? N -3--30A010

Dermochelys coriacea

112100001M AC11E0A0AQ

Dogania_subplana

0110110??1 -BAC-0DABF

Emydura_macquarii

021021000- -A10-0B01P

Emydura_subglobosa

021021001- -1-2-0A0AP
Emys orbicularis

$011012100 \mathrm{~N}$-C02D0F01C

Eretmochelys_imbricata

011021011G AE-210A014

Graptemys_geographica

0110210010 03??A0FA1N 0Q113--C1C

Graptemys_pseudogeographica

0????????C 0-???0A014 OPD-3??A1?

Hydromedusa_tectifera

0210111000 03-2A0C01? 0Q1F---?0B

Kinosternon_leucostomum

0 ???????C 03--K0AA1E 0DDCD-AA10

Kinosternon_scorpioides

0110110??C 03--KOAA1E ODDCD-AA1?

Lepidochelys_kempii

0110??0?00 0----0A010 0F33-??-10

Lissemys_punctata

01101100?A 00A2-0DABF

Macrochelys_temminckii

01102101?0 03??10M01K 0B11P?101B B0

Malaclemys terrapin litoralis

011??????C 03-2B0A01M OND-E--A1?

Mauremys caspica

0110??01?C 03-200A01N

Mauremys rivulata

0?????1?0 03??A0F01B OY1-4-??1B

Mesoclemmys nasuta

0010?10100-03--20A01S OWD?M?0304

Pelodiscus_sinensis

011011001B 0DA2G0DACC OKD1BA?B1B

Pelomedusa_subrufa

021002000A 03-2-0A0AR OD11K0-D0D

Pelusios_niger

0210210000 03---0A014 1KD14---04

Pelusios_sinuatus

0210210000 03??A0G010 0G11G01D0A B01K01----

$001 \mathrm{HP}---01$

?01------0

2? ?DD?---0

$\mathrm{A} 00 \mathrm{O}-\mathrm{H} ?--$ ?

?01-Q---10

?11A01----

B01GN-2-1

B011H1--?-

B011M-20--

$001 \mathrm{C00----}$

?0?KD1----

?01401---1

A02P01----

?011G1---?

2 ? -0? ?---1

-------- 0

$2000-? ?--?$

OAABAAAOOA

M1010A---2

$-A$ ????100 2?--

---AD-111-

-- BA1A-00

---B71-0-1

---BG----0

$1--B 70---$ ?

$---0-----0$

?BO------?

?02101--??

?--------?

C02101--?-

-00300-0-?

B1?E01----

BO?EEO-O--

B01M00----

B021B12A?-

001A00----

B0?101----

?011G1---?

B01EA10---

B02101--??

?02101--?-

B01141----

B11E01----

B 0 ?NM1 --11

?02101--??

B02101--??

$\mathrm{B} 0$ ? 1C1A10?

?021E1-0--

B12F01----

B011E0-0--

?011K1----

??1A00B005 ????

??0120200? ??0-

?A100100? ??0?

????02010 0?3A

A1111?0AE B-0-

??????010 0-3A

-001011000 E?--

-- ????011 -AD1

--111 A???? ??-?

5A010A---- --11000000 C-0-

-00107B--? ?-1000301- -?--

-0010??--? ?-01000??0 2-??

-00104---? ?-0????000 1---

6A0A03-??- --1A0OBOAD O?C?

$---\mathrm{E} 6-----\quad-0$ ???6---C -A??????0- ?-B1

---0C1---0 60011A?--- ?0?????100 2-0-

---071---? -0011Q---3 --1101A000 C-00

---03----1 800101B--- ??A1003000 B--?

---D1----1 -1010A---2 ?01100?000 0---

---03----1 8001172--A 1A??????00 2-31

?20-----? -0010??--? ????????? ??-?

---F4---- -0010F---A 0A?????00B A131

$----8----? \quad-0010$ P2--? ??0?????? ??-?

$----8----? \quad-0010$ P2--? ??0????000 2---

$-\mathrm{AAOH}----1 \quad 81011 \mathrm{~A}---? \quad$ ??1?002??0 A---

---E6----? -000-E301C -A110?3100 F-BB

OA1F----- -001-A---C -A0000201C D1A-

?-------? -001072--? ??0????000 B---

?-------? -0011??--B A00????000 B?--

?--AG----0 F0011A---3 --??????00 2--?

--------? -0010K---? ??1?000000 2--?

---C6-1101 100A0A---C -A?????1A0 E-EC

---GB1---1 D001AM---B 0001?0300E E-B1

-101071--? ??11013??? ???-

G00003---? ???????01B 120? 


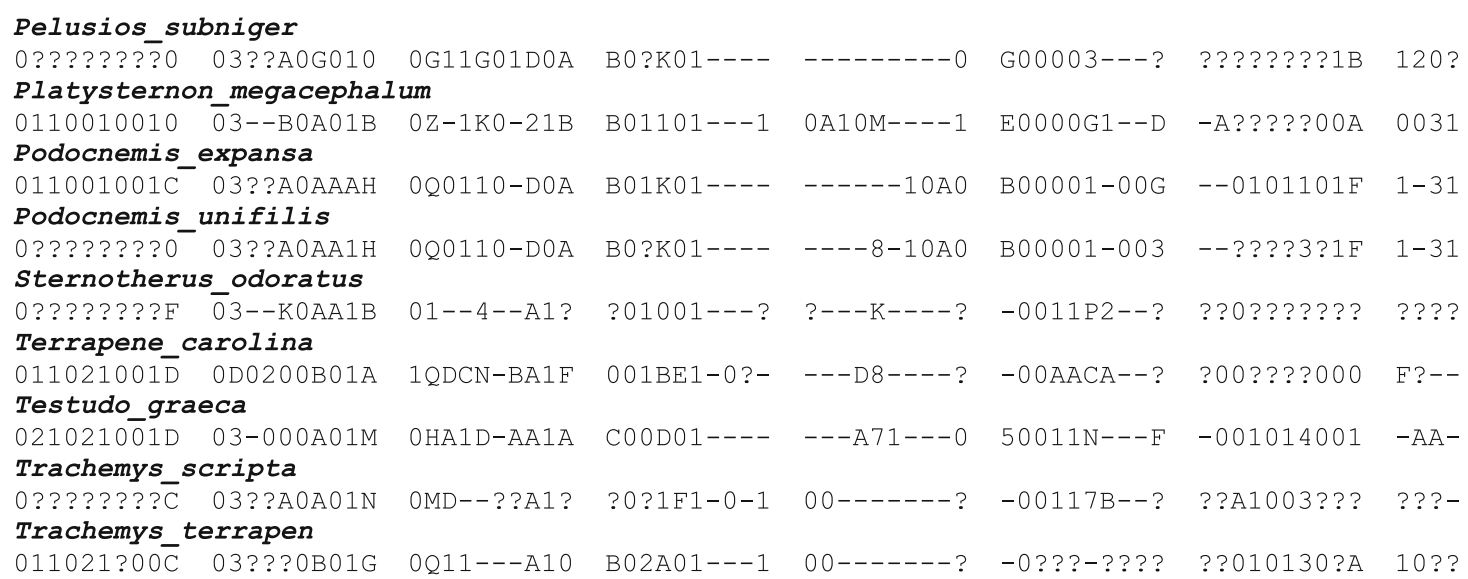

\section{References}

Abdala, V., \& Moro, S. (1996). Cranial musculature of South American Gekkonidae. Journal of Morphology, 229, 59-70.

Abdala, V., \& Moro, S. (2003). A cladistic analysis of ten lizard families (Reptilia: Squamata) based on cranial musculature. Russian Journal of Herpetology, 10(1), 53-78.

Adams, L. A. (1919). A memoir on the phylogeny of the jaw muscles in recent and fossil vertebrates. Annals New York Academy of Science, 28, 51-166, 113 plates.

Anderson, H. T. (1936). The jaw musculature of the phytosaur, Machaeroprosopus. Journal of Morphology, 59(3), 549-587.

Asher, R. J., Maree, S., Bronner, G., Bennett, N. C., Bloomer, P., Czechowski, P., Meyer, M., \& Hofreiter, M. (2010). A phylogenetic estimate for golden moles (Mammalia, Afrotheria, Chrysochloridae). BMC Evolutionary Biology, 10(69), doi:10.1186/ 1471-2148-1110-1169.

Ashley, L. M. (1962). Laboratory Anatomy of the Turtle. New York: McGraw-Hill.

Assis, L. C. S., \& Rieppel, O. (2011). Are monophyly and synapomorphy the same or different? Revisiting the role of morphology in phylogenetics. Cladistics, 27(1), 94-102. doi:10.1111/j.10960031.2010.00317.x.

Bojanus, L. H. (1819-1821). Anatome Testudines Europaeae. Vilnae: Impensis auctoris. Typis Josephi Zawazki, Typographi Universitatis.

Brinkman, D. B., \& Wu, X.-C. (1999). The skull of Ordosemys, an Early Cretaceous turtle from Inner Mongolia, People's Republic of China, and the interrelationships of Eucryptodira (Chelonia, Cryptodira). Paludicola, 2, 134-147.

Burkard, O. (1902). Ueber die Periorbita der Wirbeltiere und ihre musculösen Elemente. Archiv für Anatomie und Physiologie / Anatomische Abteilung (Archiv für Anatomie und Entwickelungsgeschichte), Supplement, 79-97.

Burne, R. H. (1905). Notes on the muscular and visceral anatomy of leathery turtle (Dermochelys coriacea). Proceedings of the Zoological Society of London, 291-324.

Busbey, A. B., III. (1989). Form and function of the feeding apparatus of Alligator mississippiensis. Journal of Morphology, 202, 99-127.

Costelli, J. (1973). Iguanid Trigeminal Musculature and Its Role in the Phylogeny of the Iguanidae. UMI Dissertation Services, Bell and Howell, Ann Arbor, MI.

Daza, J. D., Diogo, R., Johnston, P., \& Abdala, V. (2011). Jaw adductor muscles across lepidosaurs: a reappraisal. Anatomical Record, 294, 1765-1782.

De Pinna, M. C. C. (1991). Concepts and tests of homology in the cladistic Paradigm. Cladistics, 7, 367-394.
Diogo, R. (2004). Muscles versus bones: catfishes as a case study for a discussion on the relative contribution of myological and osteological features in phylogenetic reconstructions. Animal Biology, $54,373-391$.

Diogo, R. (2007). Homoplasies, consistency index and the complexity of morphological evolution: catfishes as a case study for general discussions on phylogeny and macroevolution. International Journal of Morphology, 25, 831-837.

Diogo, R. (2008). Origin of higher clades-osteology, myology, phylogeny and evolution of bony fishes and the rise of tetrapods. Enfield: Science.

Diogo, R., \& Abdala, V. (2010). Muscles of Vertebrates. Boca Bacon, New York

Diogo, R., \& Wood, B. (2011). Soft-tissue anatomy of the primates: phylogenetic analyses based on the muscles of the head, neck, pectoral region and upper limb, with notes on the evolution of these muscles. Journal of Anatomy, 219(3), 273-359. doi:10.1111/j.1469-7580.2011.01403.x.

Diogo, R., Abdala, V., Lonergan, N., \& Wood, B. A. (2008). From fish to modern humans - comparative anatomy, homologies and evolution of the head and neck musculature. Journal of Anatomy, 213, 391-424.

Diogo, R., Doadrio, I., \& Vandewalle, P. (2008). Teleostean phylogeny based on osteological and myological characters. International Journal of Morphology, 26, 463-522.

Edgeworth, F. H. (1911). On the morphology of the cranial muscles in some vertebrates. Quarterly Journal of Microscopical Science, $s 2-56(222), 167-316$.

Edgeworth, F. H. (1935). The Cranial Muscles of Vertebrates. London: Cambridge University Press.

Eernisse, D. J., \& Kluge, A. G. (1993). Taxonomic congruence versus total evidence, and amniote phylogeny inferred from fossils, molecules, and morphology. Molecular Biology and Evolution, 10(6), 1170-1195.

Estes, R., de Queiroz, K., \& Gauthier, J. (1988). Phylogenetic relationships within Squamata. In R. Estes \& G. Pregill (Eds.), The Phylogenetic Relationships of the Lizard Families (pp. 119281). Palo Alto: Stanford University Press.

Fisher, H. I., \& Goodman, D. C. (1955). The myology of the Whooping Crane, Grus americana. Illinois Biological Monographs, 24(2), 127.

Fritz, U., \& Havaš, P. (2007). Checklist of chelonians of the world. Vertebrate Zoology, 57(2), 149-368.

Frost, D. R., Grant, T., Faivovich, J., Bain, R. H., Haas, A., Haddad, C. F. B., et al. (2006). The amphibian tree of life. Bulletin of the American Museum of Natural History, 297, 1-370.

Gaffney, E. S. (1975). A phylogeny and classification of the higher categories of turtles. Bulletin of the American Museum of Natural History, 155(5), 387-436. 
Gaffney, E. S. (1979). Comparative cranial morphology of recent and fossil turtles. Bulletin of the American Museum of Natural History, 164(2), 67-376.

Gaffney, E. S., \& Meylan, P. A. (1988). A phylogeny of turtles. In M. J. Benton (Ed.), The phylogeny and classification of the tetrapods. Volume 1: Amphibians, reptiles, birds (Vol. Special Vol. 35A, pp. 157-219). Oxford: Clarendon.

Gaffney, E. S. (1990). The comparative osteology of the Triassic turtle Proganochelys. Bulletin of the American Museum of Natural History, 194, 1-263.

Gaffney, E. S., Meylan, P. A., \& Wyss, A. R. (1991). A computer assisted analysis of the relationships of the higher categories of turtles. Cladistics, 7(313-335)

Gaunt, A. S., \& Gans, C. (1969). Mechanics of respiration in the snapping turtle, Chelydra serpentina (Linné). Journal of Morphology, 128, 195-228.

George, J., \& Shah, R. (1955a). The myology of the head and the neck of the common indian pond turtle, Lissemys punctata granosa SCHOEPFF. The Journal of Animal Morphology and Physiology, 1(1), 1-12.

Gnanamathu, M. A. (1937). Comparative study on the hyoid and tongue of some genera of reptiles. Proceedings of the Zoological Society of London, Series B, 107, 1-63.

Haas, G. (1973). Muscles of the jaws and associated structures in the Rhynchocephalia and Squamata. In C. Gans (Ed.), Biology of the Reptilia (Vol. 4, pp. 285-490, Morphology D). London: Academic.

Haas, A. (2001). Mandibular arch musculature of anuran tadpoles; with comments on homologies of amphibian jaw muscles. Journal of Morphology, 247, 1-33.

Haas, A. (2003a). Phylogeny of frogs as inferred from primarily larval characters (Amphibia: Anura). Cladistics, 19, 23-89.

Haas, A. (2003b). The Phylogeny of Frogs and the Evolution of Anuran Larvae. Habilitation, Friedrich-Schiller-Universität, Jena.

Hacker, G. (1954). Über Kiefermuskulatur und Mundfascien bei Testudo graeca. $\mathrm{PhD}$ (medicine), Ernst-Moritz-Arndt-Universität Greifswald.

Hacker, G., \& Schumacher, G.-H. (1954). Die Muskeln und Fascien des Mundbodens bei Testudo graeca. Anatomischer Anzeiger, 101, 294-305.

Hertwig, S. T. (2005). Die Evolution der Kiefermuskulatur der Cyprinodontiformes (Teleostei, Acanthopterygii) unter phylogenetischen und funktionsmorphologischen Aspekten (pp. 1-170). Jena: Friedrich-Schiller-Universtität.

Hertwig, S. T. (2008). Phylogeny of the Cyprinodontiformes (Teleostei, Atherinomorpha): the contribution of cranial soft tissue characters. Zoologica Scipta, 37(2), 141-174.

Hofer, H. (1950). Zur Morphologie der Kiefermuskulatur der Vögel. Zoologische Jahrbücher, Abteilung für Anatomie und Ontogenie der Tiere, 70, 427-556.

Hoffmann, C. K. (1890). Reptilien. 1. Schildkröten (Vol. 6(3), Dr. H.G. Bronn's Klassen und Ordnungen des Thier-Reichs, wissenschaftlich dargestellt in Wort und Bild). Leipzig: C.F. Winter'sche Verlagshandlung.

Holliday, C. M., \& Witmer, L. M. (2007). Archosaur adductor chamber evolution: integration of musculoskeletal and topological criteria in jaw muscle homology. Journal of Morphology, 268(6), 457484. doi:10.1002/Jmor.10524.

Hoyos, J. M. (1990). Estudio cladístico en la familia Iguanidae (Sauria, Reptilia) con base en la musculatura del miembro posterior. . Revista de la. Academia Colombiana de Ciencias Exactas, Físicas y Naturales, 17(66), 543-558.

Hoyos, J. M. (1998). A repraisal of the phylogeny of lizards of the family Gymnophthalmidae (Sauria, Scincomorpha). Revista Española de Herpetología, 12, 27-43.

Hoyos, J. M. (1999). The mandibular trigeminus branch and the mandibular adductor muscles. Topograpic conditions in Ranidae (Anura: Ranidae) Herpetozoa, 12(1/2), 67-71.
Iordansky, N. N. (1964). The jaw muscles of the crocodiles and some relating structures of the crocodilian skull. Anatomischer Anzeiger, 115, 256-280.

Iordansky, N. N. (1987). Morphological and functional features of mandibular apparatus in turtles (Reptilia, Chelonia) and the problem of their origin [in Russian] (english abstract). Zoologichesky Zhurnal, 66(11), 1716-1729.

Iordansky, N. N. (1994). Tendons of jaw muscles in Amphibia and Reptilia: homology and evolution. Russian Journal of Herpetology, 1(1), 13-20.

Iordansky, N. N. (1996). Jaw musculature of turtles: structure, functions, and evolutionary conservatism. Russian Journal of Herpetology, 3(1), 49-57.

Iordansky, N. N. (2000). Jaw muscles of the crocodiles: structure, synonymy, and some implications on homology and functions. Russian Journal of Herpetology, 7(1), 41-50.

Iordansky, N. N. (2008). Intramandibular muscles and some problems in the evolution of the jaw apparatus in vertebrates [in Russian]. Zoologičeskij žurnal, 87(1), 49-61.

Iordansky, N. N. (2010). Pterygoideus muscles and other jaw adductors in amphibians and reptiles [English version of Russian original text]. Biology Bulletin, 37(9), 905-914.

Iverson, J. B., Brown, R. M., Akre, T. S., Near, T. J., Le, M., Thomson, R. C., et al. (2007). In search of the tree of life for turtles. Chelonian Research Monographs, 4, 85-106.

Johnston, P. (2011a). New morphological evidence supports congruent phylogenies and Gondwana vicariance for palaeognathous birds. Zoological Journal of the Linnean Society, 163(3), 959-982. doi:10.1111/j.1096-3642.2011.00730.x.

Johnston, P. (2011b). Cranial muscles of the anurans Leiopelma hochstetteri and Ascaphus truei and the homologies of the mandibular adductors in Lissamphibia and other gnathostomes. Journal of Morphology, 272, 1492-1512.

Jones, M. E. H., Curtis, N., O'Higgins, P., Fagan, M., \& Evans, S. E. (2009). The head and neck muscles accociated with feeding on Sphenodon (Reptilia: Lepidosauria: Reynchocephalia). Palaeontologia Electronica, 12(2), 7A:56p, http://palaeo-electronica.org/ $20092 / 179$

Jones, M. E. H., Werneburg, I., Curtis, N., Penrose, R., O'Higgins, P., Fagan, M. J., Evans S. E., et al. (2012). The head and neck anatomy of sea turtles (Cryptodira: Chelonioidea) and skull shape in Testudines. PLoS ONE, in press.

Joyce, W. G. (2007). Phylogenetic relationships of mesozoic turtles. Bulletin of the Peabody Museum of Natural History, 48(1), 3-102.

Joyce, W. G., \& Sterli, J. (2011, in press). Congruence, non-homology, and the phylogeny of basal turtles. Acta Zoologica, doi:10.1111/ j.1463-6395.2010.00491.x.

Joyce, W. G., Parham, J. F., \& Gauthier, J. A. (2004). Developing a protocol for the conversion of rank-based taxon names to phylogenetically defined clade names, as exemplified by turtles. Journal of Paleontology, 78(5), 989-1013.

Kesteven, H. L. (1942-1945). The evolution of the skull and the cephalic muscles. The Australian Museum Memoirs, 8(1-4), 1-316.

Kilias, R. (1957). Die funktionell-anatomische und systematische Bedeutung der Schläfenreduktion bei Schildkröten. Mitteilungen aus dem Zoologischen Museum in Berlin, 33(2), 307354.

Kornet, D. J., \& Turner, H. (1999). Coding polymorphism for phylogeny reconstruction. Systematic Biology, 48(2), 365-379.

Krenz, J. G., Naylor, G. J. P., Shaffer, B. S., \& Janzen, F. J. (2005). Molecular phylogenetics and evolution of turtles. Molecular Phylogenetics and Evolution, 37, 178-191.

Lakjer, T. (1926). Studien über die Trigeminus-versorgte Kaumuskulatur der Sauropsiden. Copenhagen: Reitsel.

Lemell, P., Lemell, C., Snelderwaard, P., Gumpenberger, M., Wochesländer, R., \& Weisgram, J. (2002). Feeding patterns 
of Chelus fimbriatus (Pleurodira: Chelidae). Journal of Experimental Biology, 205, 1495-1506.

Lemell, P., Beisser, C. J., Gumpenberger, M., Snelderwaard, P., Gemel, R., \& Weisgram, J. (2010). The feeding apparatus of Chelus fimbriatus (Pleurodira; Chelidae) —adaptation perfected? Amphibia-Reptilia, 31, 97-107.

Li, C., Wu, X.-C., Rieppel, O., Wang, L.-T., \& Zhao, L.-J. (2008). An ancestral turtle from the Late Triassic of southwestern China. Nature, 456, 497-501.

Lubosch, W. (1933). Untersuchungen über die Visceralmuskulatur der Sauropsiden. Morphologisches Jahrbuch, 72, 584-666.

Lubosch, W. (1938a). Amphibien und Sauropsiden. In L. Bolk, E. Göppert, E. Kallius, \& W. Lubosch (Eds.), Handbuch der vergleichenden Anatomie der Wirbeltiere (Vol. Teil 5 Skelettsystem II, Muskelsystem, Urogenitalsystem I pp. 1025-1064). Berlin: Urban \& Schwarzenberg.

Lubosch, W. (1938b). Säugetiere. In L. Bolk, E. Göppert, E. Kallius, \& W. Lubosch (Eds.), Handbuch der vergleichenden Anatomie der Wirbeltiere (Vol. Teil 5 Skelettsystem II, Muskelsystem, Urogenitalsystem I pp. 1065-1106). Berlin: Urban \& Schwarzenberg.

Luther, A. (1938). Acranier, Cyclostomaen, Selachier, Holocephalen, Ganoiden und Dipnoer. In L. Bolk, E. Göppert, E. Kallius, \& W. Lubosch (Eds.), Handbuch der vergleichenden Anatomie der Wirbeltiere (Vol. Teil 5 Skelettsystem II, Muskelsystem, Urogenitalsystem I pp. 467-542). Berlin: Urban \& Schwarzenberg.

Lyson, T., Bever, G. S., Bhullar, B.-A. S., Joyce, W. G., \& Gauthier, J. A. (2010). Transitional fossils and the origin of turtles. Biology Letters. doi:10.1098/rsbl.2010.0371(6), 830-833.

Maddison, W. P., \& Maddison, D. R. (2007). Mesquite: a modular system for evolutionary analysis. $2.01 \mathrm{ed}$.

Meckel, J. F. (1828). System der vergleichenden Anatomie. Dritter Theil. Halle: Rehgerschen.

Mickoleit, G. (2004). Phylogenetische Systematik der Wirbeltiere. München: Verlag Dr. Friedrich Pfeil.

Mivart, S. G. (1867). Notes on the myology of Iguana tuberculata. Proceedings of the Zoological Society of London, 766-797.

Müller, W., \& Weber, E. (1998). Re-discovery of a supposedly lost muscle in palaeognathous birds and its phylogenetic implications. Mitteilungen des Museums für Naturkunde Berlin, Zoologische Reihe, 74(1), 11-18.

Ogushi, K. (1913). Anatomische Studien an der japanischen dreikralligen Lippenschildkröte (Trionyx japanicus). II. Mitteilung: Muskel- und peripheres Nervensystem. Morphologisches Jahrbuch, 46(Heft 3+4), 299-562.

Owen, R. (1866). On the Anatomy of Vertebrates. Fishes and reptiles (Vol. 1). London: Longmans.

Parham, J. F., Feldman, C. R., \& Boore, J. L. (2006). The complete mitochondrial genome of the enigmatic bigheaded turtle (Platysternon): description of unusual genomic features and the reconciliation of phylogenetic hypotheses based on mitochondrial and nuclear DNA. Bmc Evolutionary Biology, 6, 1-11.

Pleijel, F. (1995). On character coding for phylogeny reconstruction. Cladistics, 11, 309-315.

Poglayen-Neuwall, I[Ivo]. (1953/54). Die Besonderheiten der Kiefermuskulatur von Dermochelys coriacea. Anatomischer Anzeiger, $100,22-32$.

Poglayen-Neuwall, I[ngeborg]. (1953). Untersuchungen über die Trigeminusmuskulatur von Hatteria. Zeitschrift für wissenschaftliche Zoologie, 157(1), 57-76.

Poglayen-Neuwall, I[ngeborg]. (1954). Die Kiefermuskulatur der Eidechsen und ihre Innervation. Zeitschrift für wissenschaftliche Zoologie, 158(1), 79-132.

Poglayen-Neuwall, I[vo]. (1953a). Untersuchungen der Kiefermuskulatur und deren Innervation bei Schildkröten. Acta Zoologica, 34, 241-292.
Poglayen-Neuwall, I[vo]. (1953b). Untersuchungen der Kiefermuskulatur und der Innervation an Krokodilen. Anatomischer Anzeiger, 99(16/17), 257-276.

Poglayen-Neuwall, I[vo]. (1966). Bemerkungen zur Morphologie und Innervation der Trigeminusmuskulatur von Chelus fimbriatus (Schneider). Zoologische Beiträge, 12, 43-65.

Rathke, H. (1848). Ueber die Entwickelung der Schildkröten. Braunschweig: Vieweg.

Ray, C. E. (1959). A sesamoid bone in the jaw musculature of Gopherus polyphemus (Reptilia: Testudininae). Anatomischer Anzeiger, 107, 85-91.

Rieppel, O. (1981). Die Funktion des Kragens der Ceratopsida. In Funktionsmorphologie (Vol. 1, pp. 205-216, Paläontologische Kursbücher). München: Paläontologische Gesellschaft Selbstverlag.

Rieppel, O. (1987). The development of the trigeminal jaw adductor musculature and associated skull elements in the lizard Podarcis sicula. Journal of Zoology, 212, 131-150.

Rieppel, O. (1990). The structure and development of the jaw adductor musculature in the turtle Chelydra serpentina. Zoological Journal of the Linnean Society, 98, 27-62.

Rieppel, O. (2008). The relationships of turtles within amniotes. In J. Wyneken, M. H. Godfrey, \& V. Bels (Eds.), Biology of Turtles (pp. 345-353). Boca Raton: CRC.

Sánchez-Villagra, M. R., Winkler, J. D., \& Wurst, L. (2007). Autopodial skeleton evolution in side-necked turtles (Pleurodira). Acta Zoologica, 88, 199-209.

Sánchez-Villagra, M. R., Müller, H., Sheil, C. A., Scheyer, T. M., Nagashima, H., \& Kuratani, S. (2009). Skeletal development in the Chinese soft-shelled turtle Pelodiscus sinensis (Testudines: Trionychidae). Journal of Morphology, 270, 1381-1399.

Scanlon, T. C. (1982). Anatomy of the neck of the western painted turtle (Chrysemys picta belli Gray; Reptilia, Testudinata) from the perspective of possible movements in the region. $\mathrm{PhD}$-thesis, The University of Michigan, Michigan.

Scheyer, T. M. (2009). Conserved bone microstructure in the shells of long-necked and short-necked chelid turtles (Testudinata, Pleurodira). Fossil Record, 12(1), 47-57.

Scheyer, T. M., Werneburg, I., Mitgutsch, C., Delfino, M., \& SánchezVillagra, M. R. (2012). Three ways to tackle the turtle: integrating fossils, comparative embryology and microanatomy. In J. Gardner, D. Brinkman, \& P. Holroyd (Eds.), Vertebrate Paleobiology and Paleoanthropology Series. Dordrecht: Springer, in press.

Schumacher, G.-H. (1953/1954). Beiträge zur Kiefermuskulatur der Schildkröten: I. Mitteilung. Bau des M. adductor mandibularis unter spezieller Berücksichtigung des M. pterygoideus bei Chelone, Caretta, Podocnemis, Pelusios und Testudo elephantopus. Wissenschaftliche Zeitschrift der Ernst Moritz Arndt-Universität GreifswaldMathematisch-naturwissenschaftliche Reihe, 3(6/7), 457-518.

Schumacher, G.-H. (1954/1955a). Beiträge zur Kiefermuskulatur der Schildkröten: II. Mitteilung. Bau des M. adductor mandibularis unter spezieller Berücksichtigung der Fascien des Kopfes bei Platysternon megacephalum, Emys orbicularis, Testudo graeca, Pelomedusa subrufa, Clemmys caspica riculata, Graptemys gepgraphica, Hardella thurrjii, Makrochelys temminckii, Emydura krefftii, Hydromedusa tectifera, Chelodina longicollis, Trionyx punctatus, Amyda sinensis und Dogania subplana. Wissenschaftliche Zeitschrift der Ernst Moritz Arndt-Universität Greifswald Mathematisch-naturwissenschaftliche Reihe, 4(5), 501-518.

Schumacher, G.-H. (1954/1955b). Beiträge zur Kiefermuskulatur der Schildkröten: III. Mitteilung. Bau des M. adductor mandibularis bei Macrochelys temminckii, Platysternon megacephalum, Clemmys caspica rivulata, Emys orbicularis, Graptemys geographica, Hardella thurjii, Testudo graeca, Amyda sinensis, Dogania subplana, Trionyx punctatus, Pelomedusa subrufa, Chelodina longicollis, $\mathrm{Hy}$ dromedusa tectifera und Emydura krefftii. Wissenschaftliche 
Zeitschrift der Ernst Moritz Arndt-Universität Greifswald Mathematisch-naturwissenschaftliche Reihe, 4(6/7), 559-588.

Schumacher, G.-H. (1956a). Kritische Stellungennahme zu der Arbeit von Poglayen-Neuwall "Untersuchungen der Kiefermuskulatur und deren Innervation bei Schildkröten". Acta Zoologica, 37, 1-42.

Schumacher, G.-H. (1956b). Morphologische Studie zum Gleitmechanismus des M. adductor mandibulae externus bei Schildkröten. Anatomischer Anzeiger, 103(1/4), 1-12.

Schumacher, G.-H. (1956c). Über die Fascien des Kopfes der Schildkröten nebst einigen Bemerkungen zu der Arbeit von Lakjer 1926. Zoologischer Anzeiger, 156(3-4), 35-54.

Schumacher, G.-H. (1972). Die Kopf- und Halsregion der Lederschildkröte Dermochelys coriacea (LINNAEUS 1766) - Anatomische Untersuchungen im Vergleich zu anderen rezenten Schildkröten - Mit 7 Figuren im Text und 31 Tafeln (Vol. 2, Abhandlungen der Akademie der Wissenschaften der DDR). Berlin: Akademie.

Schumacher, G.-H. (1973). The head muscles and hyolaryngeal skeleton of turtles and crocodilians. In C. Gans (Ed.), Biology of the Reptilia (Vol. 4, pp. 101-199, Morphology D). London: Academic.

Shaffer, H. B. (2009). Turtles (Testudines). In S. B. Hedges \& S. Kumar (Eds.), The timetree of life (pp. 398-401). Oxford: Oxford University Press.

Shaffer, H. B., Meylan, P., \& McKnight, M. L. (1997). Tests of turtle phylogeny: Molecular, morphological, and paleontological approaches. Systematic Biology, 46, 234-268.

Stannius, H. (1854). Die Wirbeltiere (2. ed., Handbuch der Zootomie). Berlin: von Veit.

Sterli, J. (2010). Phylogenetic relationships among extinct and extant turtles: the position of Pleurodira and the effects of the fossils on rooting crown-group turtles. Contributions to Zoology, 79, 93-106.

Sterli, J., \& de la Fuente, M. (2010). Anatomy of Condorchelys antiqua STERLI, 2008, and the origin of the modern jaw closure mechanism in turtles. Journal of Vertebrate Paleontology, 30(2), 351-366.

Sterli, J., \& Joyce, W. G. (2007). The cranial anatomy of the Early Jurassic turtle Kayentachelys aprix. Acta Palaeontologica Polonica, 52(4), 675-694.

Swofford, D. L. (2003). PAUP*. Phylogenetic analysis using parsimo$n y$ (*and other methods) (4th ed.). Sunderland: Sinauer.

Thomson, J. T. (1932). The Anatomy of the Tortoise. The Scientific Proceedings of the Royal Dublin Society. New Series, 20(28), 359-461, 324 plates.

Thomson, R. C., \& Shaffer, H. B. (2010). Sparse supermatrices for phylogenetic inference: taxonomy, alignment, rogue taxa, and the phylogeny of living turtles. Systematic Biology, 59(1), 42-58.

Tvarožková, B. (2006). Development of the Temporal Emargination in Turtles and the Temporal Fenestration in Crocodilians: The origin of an Anapsid-Like Chelonian Skull. Masters thesis, Charles University in Prague, Prague.
Vetter, B. (1878). Untersuchungen zur vergleichenden Anatomie der Kiemen- und Kiefermuskulatur der Fische, 2. Teil. Jenaer Zeitschrift der Naturwissenschaften, 12, 309-332.

Webb, M. (1957). The ontogeny of the cranial bones, cranial peripheral and cranial parasympathetic nerves, together with a study of the visceral muscles of Struthio. Acta Zoologica, 38, 81-203.

Werneburg, I. (2009). Vergleichende Morphologie der Kiefermuskulatur der Beloniformes (Teleostei, Atherinomorpha) - incl. extended English summary. Saarbrücken: VDM Verlag Dr. Müller. / Digitale Bibliothek Thüringen: http://www.db-thueringen.de/servlets/ DocumentServlet?id=11300.

Werneburg, I. (2010). Evolution and development of turtles: organogenesis and cranial musculature. Zürich: Scidinge Hall.

Werneburg, I. (2011). The cranial musculature in turtles. Palaeontologia Electronica, 14(2), 15a:99 pages.

Werneburg, I. (2012). Temporal bone arrangements in turtles: an overview. Journal of Experimental Zoology. Part B: Molecular and Developmental Evolution, 318, 235-249.

Werneburg, I., \& Sánchez-Villagra, M. R. (2009). Timing of organogenesis support basal position of turtles in the amniote tree of life. BMC Evolutionary Biology, 9, 82. doi:10.1186/1471-2148-9-82.

Werneburg, I., Hugi, J., Müller, J., \& Sánchez-Villagra, M. R. (2009). Embryogenesis and ossification of Emydura subglobosa (Testudines, Pleurodira, Chelidae) and patterns of turtle development. Developmental Dynamics, 238, 2770-2786. doi:10.1002/ dvdy.22104.

Wiedemann, C. R. W. (1803). Fortsetzung der anatomischen Beschreibung der Schildkröten. Archiv für Zoologie und Zootomie, 3(2), 78-102.

Wiens, J. J. (2000, editor). Phylogenetic Analysis of Morphological Data. Washington: Smithsonian Institution Press.

Wilson, L. A. B., \& Sánchez-Villagra, M. R. (2011). The evolution and phylogenetic signal of growth trajectories: the case of chelid turtles. Journal of Experimental Zoology (Mol Dev Evol), 316, 50-60.

Winkler, J. D. (2006). Testing phylogenetic implications of eggshell characters in side-necked turtles (Testudines: Pleurodira). Zoology, 109, 127-136.

Winterbottom, R. (1974). A descriptive synonymy of the striated muscles of the Teleostei. Proceedings of the Academy of Naural Sciences of Philadelphia, 125(12), 225-317.

Wyneken, J. (2001). The anatomy of sea turtles. U.S. Departement of Commerce NOAA Technical Memorandum NMFS-SEFSC-470, $1-172$.

Wyneken, J. (2003). The External Morphology, Muscoskeletal System, and Neuro-Anatomy of Sea turtles. In P. L. Lutz, J. A. Musick, \& J. Wyneken (Eds.), The Biology of Sea Turtles (Vol. 2, pp. 39-77). Boca Raton: CRC.

Zdansky, O. (1923-1925). Über die Temporalregion des Schildkrötenschädels. Bulletin of the Geological Institution of the University of Upsala, 19, 89-114. 